NCCN

\section{Palliative Care Version 1.2016}

\section{Clinical Practice Guidelines in Oncology}

Michael Levy, MD, PhD; Thomas Smith, MD;

Amy Alvarez-Perez, MD; Anthony Back, MD;

Justin N. Baker, MD; Anna C. Beck, MD; Susan Block, MD;

Shalini Dalal, MD; Maria Dans, MD; Thomas R. Fitch, MD;

Jennifer Kapo, MD; Jean S. Kutner, MD; Elizabeth Kvale, MD;

Sumathi Misra, MD; William Mitchell, MD;

Diane G. Portman, MD; Todd M. Sauer, MD;

David Spiegel, MD; Linda Sutton, MD; Eytan Szmuilowicz, MD;

Robert M. Taylor, MD; Jennifer Temel, MD;

Roma Tickoo, MD, MPH; Susan G. Urba, MD;

Elizabeth Weinstein, MD; Finly Zachariah, MD;

Mary Anne Bergman; and Jillian L. Scavone, PhD

\section{Overview}

The aim of the NCCN Guidelines for Palliative Care is to help ensure that each patient with cancer experiences the best quality of life possible throughout the illness trajectory by providing guidance for the primary oncology team. The NCCN Palliative Care Panel is an interdisciplinary group of representatives from NCCN Member Institutions, consisting of medical oncologists, hematologists, and hematologic oncologists, pediatric oncologists, neurologists and neuro-oncologists, anesthesiologists, psychiatrists and psychologists, internists, palliative care and pain management specialists, and geriatric medicine specialists. These guidelines were developed and are updated annually by the collaborative efforts of these experts based on their clinical experience and available scientific evidence.

\begin{abstract}
The NCCN Guidelines for Palliative Care provide interdisciplinary recommendations on palliative care for patients with cancer. The NCCN Guidelines are intended to provide guidance to the primary oncology team on the integration of palliative care into oncology. The NCCN Palliative Care Panel's recommendations seek to ensure that each patient experiences the best quality of life possible throughout the illness trajectory. Accordingly, the NCCN Guidelines outline best practices for screening, assessment, palliative care interventions, reassessment, and after-death care. J Natl Compr Canc Netw 2016;14(1):82-113
\end{abstract}

\section{NCCN Categories of Evidence and Consensus}

Category 1: Based upon high-level evidence, there is uniform NCCN consensus that the intervention is appropriate.

Category 2A: Based upon lower-level evidence, there is uniform NCCN consensus that the intervention is appropriate.

Category 2B: Based upon lower-level evidence, there is NCCN consensus that the intervention is appropriate.

Category 3: Based upon any level of evidence, there is major NCCN disagreement that the intervention is appropriate.

\section{All recommendations are category $2 \mathrm{~A}$ unless otherwise noted.}

Clinical trials: NCCN believes that the best management for any cancer patient is in a clinical trial. Participation in clinical trials is especially encouraged.

\section{Please Note}

The NCCN Clinical Practice Guidelines in Oncology (NCCN Guidelines ${ }^{\circledR}$ ) are a statement of consensus of the authors regarding their views of currently accepted approaches to treatment. Any clinician seeking to apply or consult the NCCN Guidelines ${ }^{\circledR}$ is expected to use independent medical judgment in the context of individual clinical circumstances to determine any patient's care or treatment. The National Comprehensive Cancer Network $^{\circledR}\left(\mathrm{NCCN}^{\circledR}\right)$ makes no representation or warranties of any kind regarding their content, use, or application and disclaims any responsibility for their applications or use in any way. The full NCCN Guidelines for Palliative Care are not printed in this issue of JNCCN but can be accessed online at NCCN.org.

(c) National Comprehensive Cancer Network, Inc. 2016, All rights reserved. The NCCN Guidelines and the illustrations herein may not be reproduced in any form without the express written permission of NCCN.

\section{Disclosures for the NCCN Palliative Care Panel}

At the beginning of each NCCN Guidelines panel meeting, panel members review all potential conflicts of interest. NCCN, in keeping with its commitment to public transparency, publishes these disclosures for panel members, staff, and NCCN itself.

Individual disclosures for the NCCN Palliative Care Panel members can be found on page 113. (The most recent version of these guidelines and accompanying disclosures are available on the NCCN Web site at NCCN.org.)

These guidelines are also available on the Internet. For the latest update, visit NCCN.org. 


\section{Journal of the National Comprehensive Cancer Network}

The NCCN Guidelines for Palliative Care were developed to facilitate the appropriate integration of palliative care into oncology practice. The guidelines outline procedures for screening, assessment, palliative care interventions, reassessment, and after-death care.

\section{Palliative Care Screening}

The primary oncology team should screen all patients at every visit for one or more of the following: 1) unmanaged symptoms; 2) moderate to severe distress related to cancer diagnosis and therapy; 3) serious comorbid physical, psychiatric, and psychosocial conditions; 4) life expectancy of 6 months or less; 5) metastatic solid tumors; 6) patient or family concerns about the course of disease and decision-making; and/or 7) patient or family requests for palliative care. Patients who meet these screening criteria and those who make a specific request for palliative care should undergo a full palliative care assessment.

Patients who do not meet these screening criteria should undergo re-screening at the next visit. In addition, the oncology team should inform patients and family members about palliative care services. Anticipation of palliative care needs and prevention of symptoms should also be discussed, and conversations regarding advance care planning should be initiated.

\section{Palliative Care Assessment}

Patients who meet screening criteria (see previous section) should undergo a comprehensive palliative care Text cont. on page 100 .

*Michael Levy, MD, PhD/Chairtf

Fox Chase Cancer Center

*Thomas Smith, MD/Vice-Chairtfp

The Sidney Kimmel Comprehensive Cancer Center at Johns Hopkins

Amy Alvarez-Perez, MD $\psi f$

Roswell Park Cancer Institute

Anthony Back, MDtf

Fred Hutchinson Cancer Research Center/

Seattle Cancer Care Alliance

Justin N. Baker, MD€

St. Jude Children's Research Hospital/

The University of Tennessee Health Science Center

Anna C. Beck, MD†

Huntsman Cancer Institute at the University of Utah

Susan Block, MDf

Dana-Farber/Brigham and Women's Cancer Center

Shalini Dalal, MDf

The University of Texas MD Anderson Cancer Center

Maria Dans, MDf

Siteman Cancer Center at Barnes-Jewish Hospital and

Washington University School of Medicine

Thomas R. Fitch, MDf

Mayo Clinic Cancer Center

Jennifer Kapo, MDfp

Yale Cancer Center/Smilow Cancer Hospital

Jean S. Kutner, MDNPf

University of Colorado Cancer Center

Elizabeth Kvale, MDf

University of Alabama at Birmingham

Comprehensive Cancer Center

Sumathi Misra, MDppf

Vanderbilt-Ingram Cancer Center

William Mitchell, MD†

UC San Diego Moores Cancer Center
Moffitt Cancer Center

Todd M. Sauer, MDf

Fred \& Pamela Buffett Cancer Center

Stanford Cancer Institute

Linda Sutton, MDtf

Duke Cancer Institute

Eytan Szmuilowicz, MDf

Robert H. Lurie Comprehensive Cancer Center of Northwestern University

Robert M. Taylor, MD $\psi f$

The Ohio State University Comprehensive Cancer Center James Cancer Hospital and Solove Research Institute

Jennifer Temel, MDtf

Massachusetts General Hospital Cancer Center

Roma Tickoo, MD, MPHDf

Memorial Sloan Kettering Cancer Center

Susan G. Urba, MDtf

University of Michigan Comprehensive Cancer Center

Elizabeth Weinstein, MDfP

Case Comprehensive Cancer Center/

University Hospitals Seidman Cancer Center and

Cleveland Clinic Taussig Cancer Institute

Finly Zachariah, MDf

City of Hope Comprehensive Cancer Center

NCCN Staff: Mary Anne Bergman and Jillian L. Scavone, PhD

KEY:

*Writing Committee Member

Specialties: †Medical Oncology; ¥Hematology/HematologyOncology; fSupportive Care, Including Palliative and Pain Management; $\phi$ Anesthesiology; €Pediatric Oncology; «Geriatric Medicine; PInternal Medicine; $\theta$ Psychiatry and Psychology, Including Health Behavior; $\psi$ Neurology/Neuro-Oncology
Diane G. Portman, MDf

David Spiegel, MD $\theta$ 


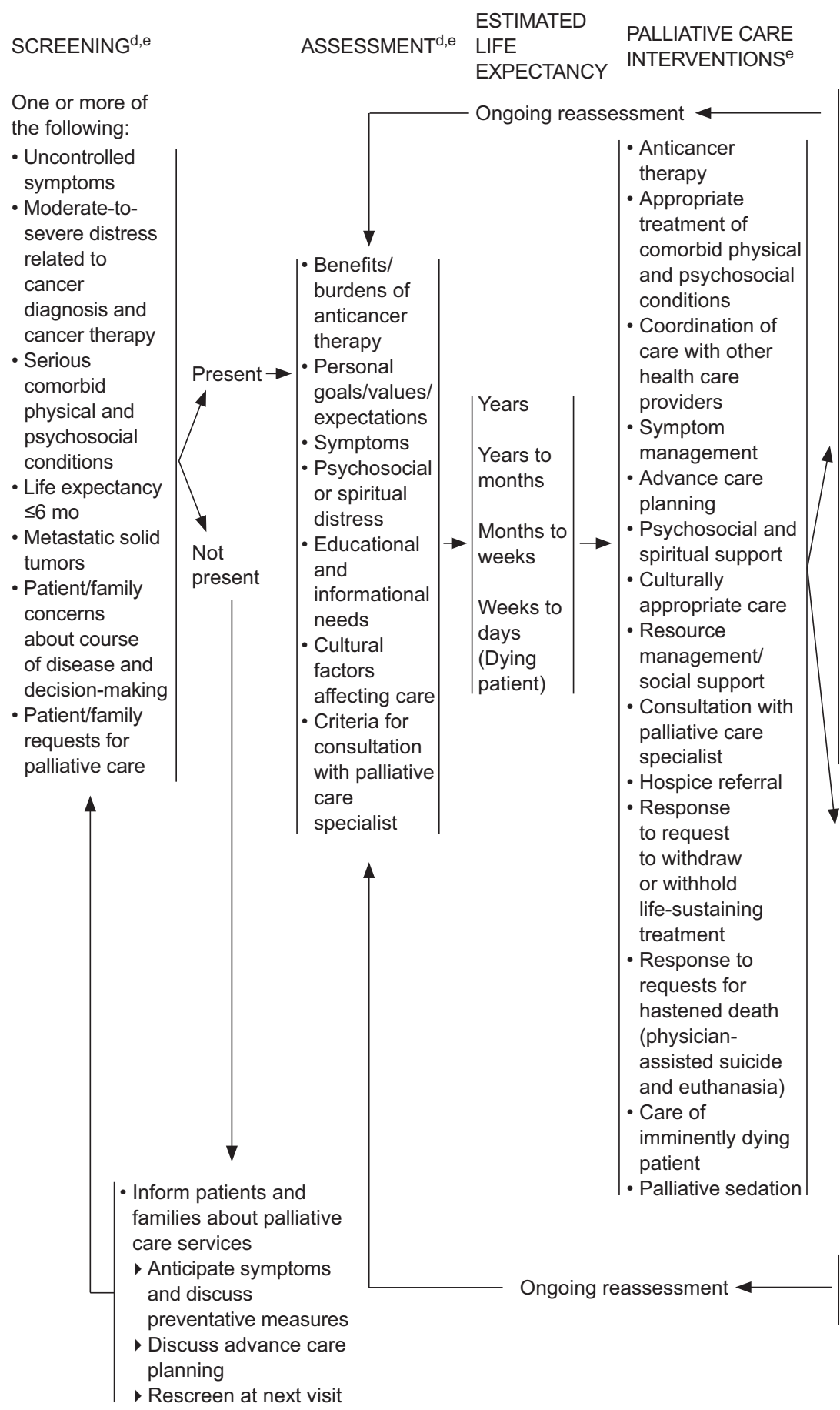

REASSESSMENT

AFTER-DEATH INTERVENTIONS

Acceptable:

- Patient

satisfied with

response to

anticancer

therapy

- Adequate

pain and

symptom

management

- Reduction of

patient/family

distress

- Acceptable

sense of

control

- Relief of

caregiver

burden

- Strengthened

relationships

- Optimized

quality of life

- Personal

growth and

enhanced

meaning

Unacceptable

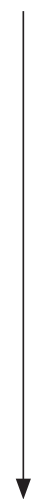

- Intensify palliative care interventions

- Consult or refer to specialized palliative

care services or hospice
For family and

caregiver(s):

- Immediate

after-death

care

- Bereavement

support

- Cancer risk

assessment

and

modification

For health care

team:

- General

support

- After-death

support

\footnotetext{
dPatients who screen positive require a care plan developed by an interdisciplinary team of physicians, nurses, social workers, and other mental health professionals, chaplains, nurse practitioners, physician assistants, and dietitians.

eOncologists should integrate palliative care into general oncology care. Early consultation/collaboration with a palliative care specialist/hospice team should be considered to improve quality of life and survival.
} 


\section{Palliative Care, Version 1.2016}

\section{SCREENING ${ }^{\mathrm{d}, \mathrm{e}}$}

- Uncontrolled symptoms

or

- Moderate-to-severe distress related to cancer diagnosis and/or cancer therapy

or

- Serious comorbid physical, psychiatric, and psychosocial conditions

or

- Metastatic solid tumors

- Life expectancy $\leq 6$ mo

- Indicators include:

$\checkmark$ Poor performance status $E C O G \geq 3$ or KPS $\leq 50$

$\diamond$ Persistent hypercalcemia

$\checkmark$ Brain or cerebrospinal fluid metastasis

$\diamond$ Delirium

$\checkmark$ Superior vena cava syndrome

$\checkmark$ Spinal cord compression

$\diamond$ Cachexia

$\diamond$ Malignant effusions

$\checkmark$ Palliative stenting or venting gastrostomy

or

- Patient/family concerns about course of disease and decision-making

or

- Patient/family requests for palliative care

\section{ASSESSMENT BY ONCOLOGY TEAM}

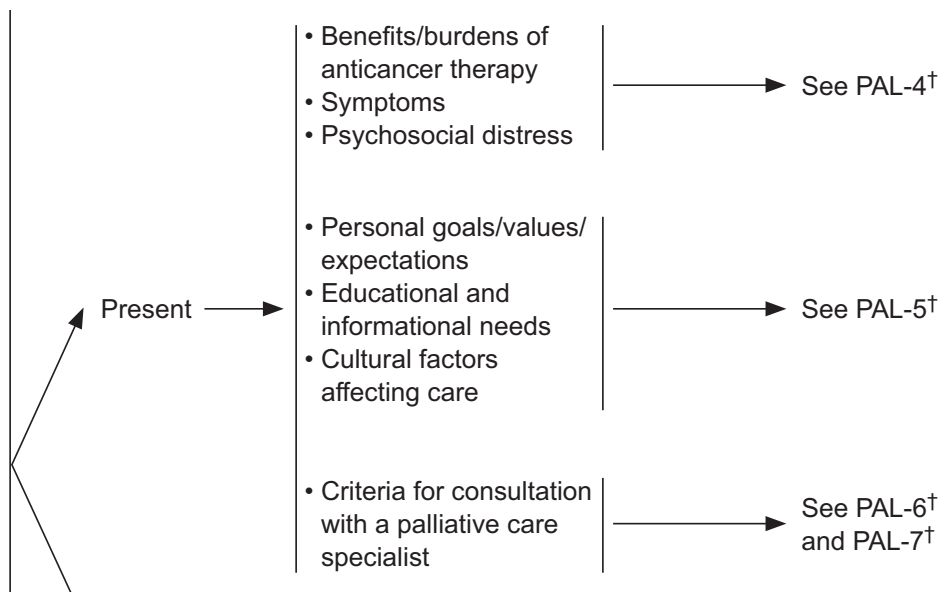

Not present

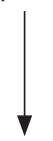

- Inform the patient and family about palliative care services

- Anticipate symptoms and discuss preventative measures

- Discuss advance care planning

- Rescreen at next visit

${ }^{\dagger}$ Available online, in these guideilnes, at NCCN.org.

dPatients who screen positive require a care plan developed by an interdisciplinary team of physicians, nurses, social workers, and other mental health professionals, chaplains, nurse practitioners, physician assistants, and dietitians.

eOncologists should integrate palliative care into general oncology care. Early consultation/collaboration with a palliative care specialist/hospice team should be considered to improve quality of life and survival.

PAL-3 
ESTIMATED

LIFE EXPECTANCY

INTERVENTIONS

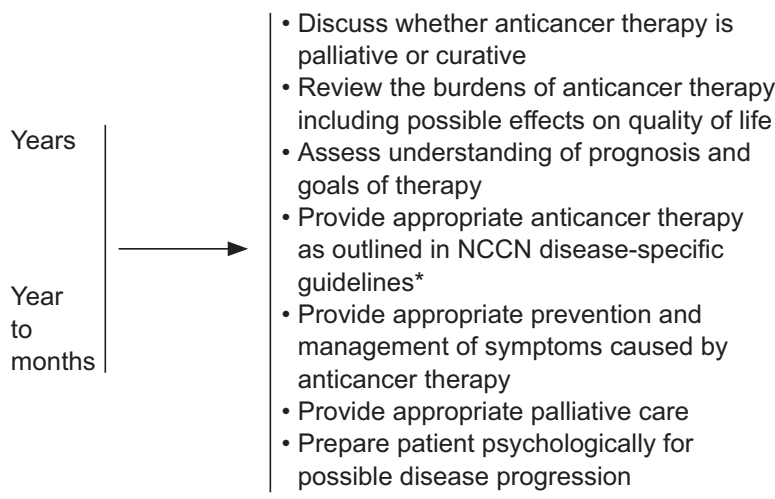

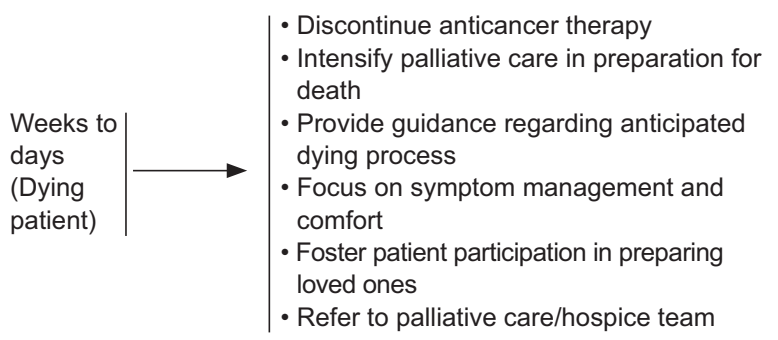

- Discontinue anticancer therapy

Months $\quad$ - Redirect goals and hopes to those that are to $\longrightarrow$ achievable based on likely prognosis and weeks $\quad$ life expectancy

- Provide guidance regarding anticipated course of disease

- Consider discontinuation of anticancer treatment

${ }^{*}$ To view the most recent version of these guidelines, visit NCCN.org.
REASSESSMENT

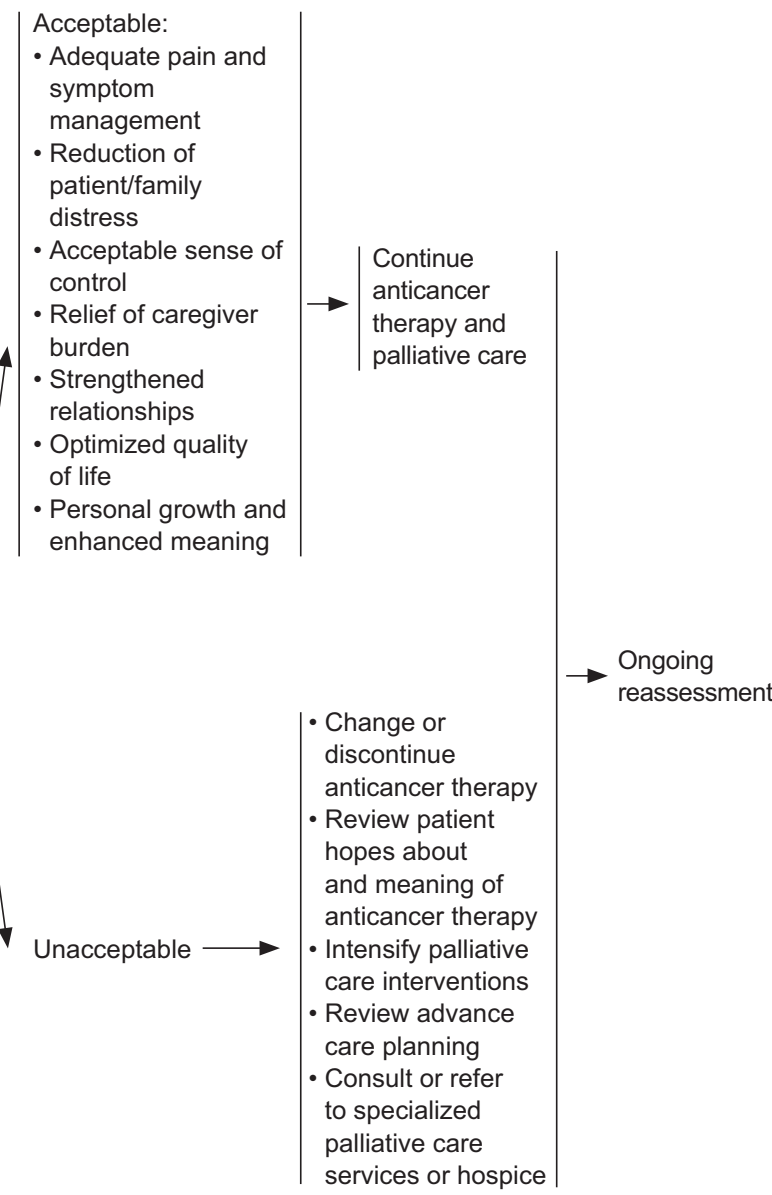

\section{PAL-9}


PAIN

\section{ESTIMATED \\ LIFE}

EXPECTANCY

INTERVENTIONS

\section{REASSESSMENT}

${ }^{*}$ To view the most recent version of these guidelines, visit NCCN.org. 


\section{DYSPNEA}

\section{ESTIMATED \\ LIFE}

EXPECTANCY

\section{INTERVENTIONS}

- Assess symptom intensity

- Treat underlying causes/comorbid

conditions:

- Radiation/chemotherapy

- Therapeutic procedure for cardiac, pleural, or abdominal fluid

- Bronchoscopic therapy

- Bronchodilators, diuretics, steroids, antibiotics, or transfusions

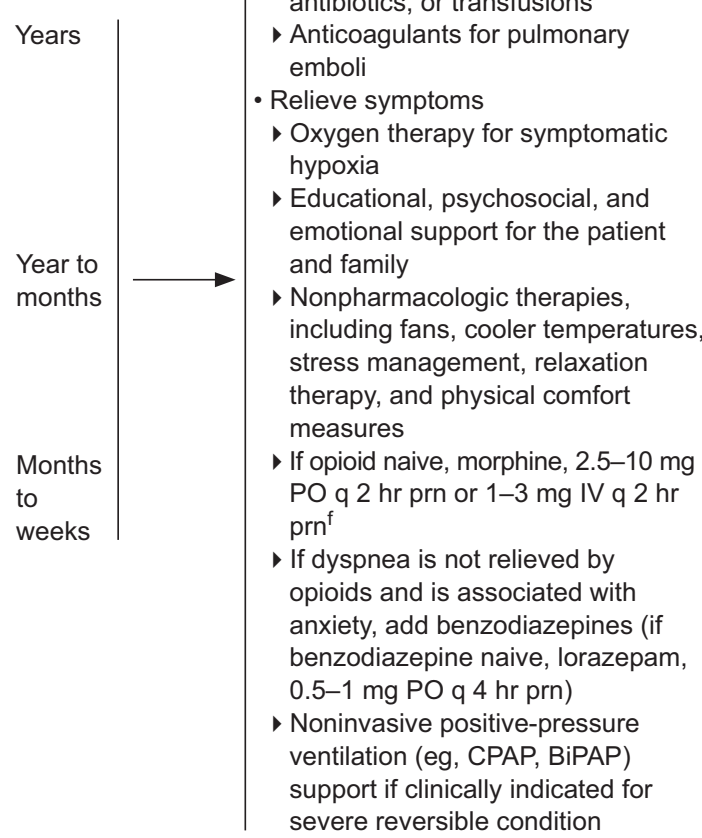

\section{REASSESSMENT}

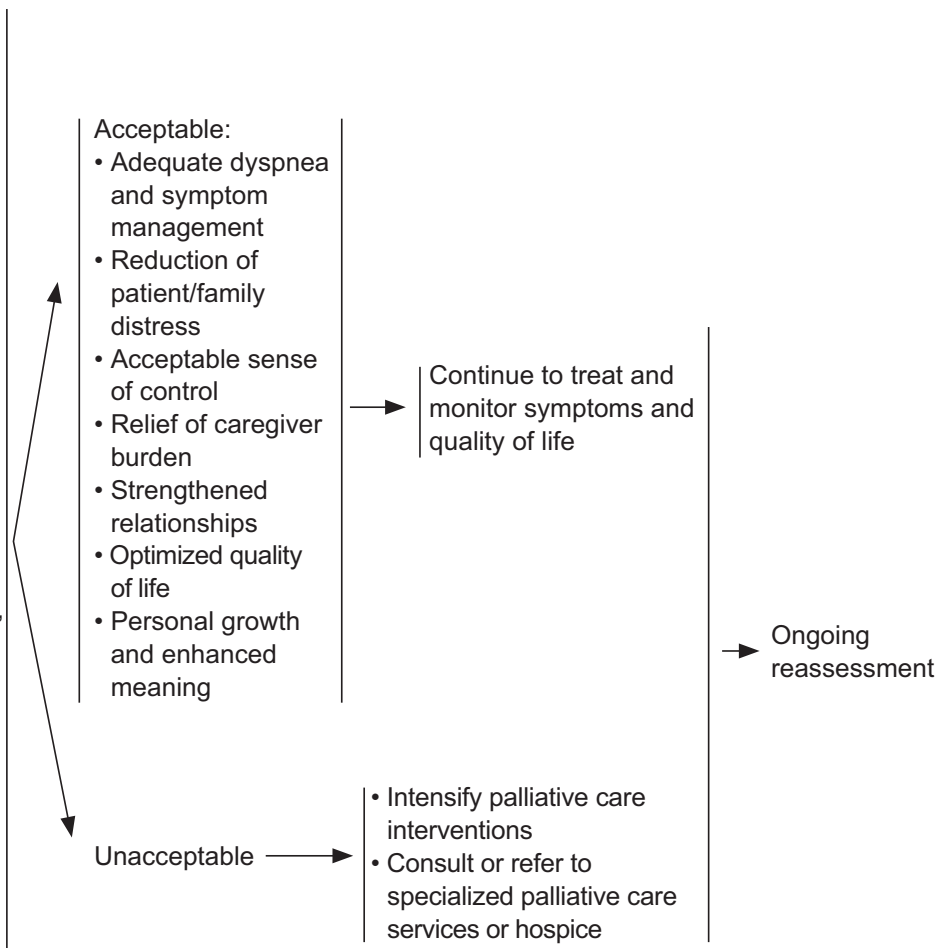

$\begin{aligned} & \text { Weeks to } \\ & \text { days } \\ & \text { (Dying } \\ & \text { patient) }\end{aligned} \mid \longrightarrow$ See Interventions (PAL-12)

fFor acute progressive dyspnea, more aggressive titration may be required.

PAL-11 
DYSPNEA

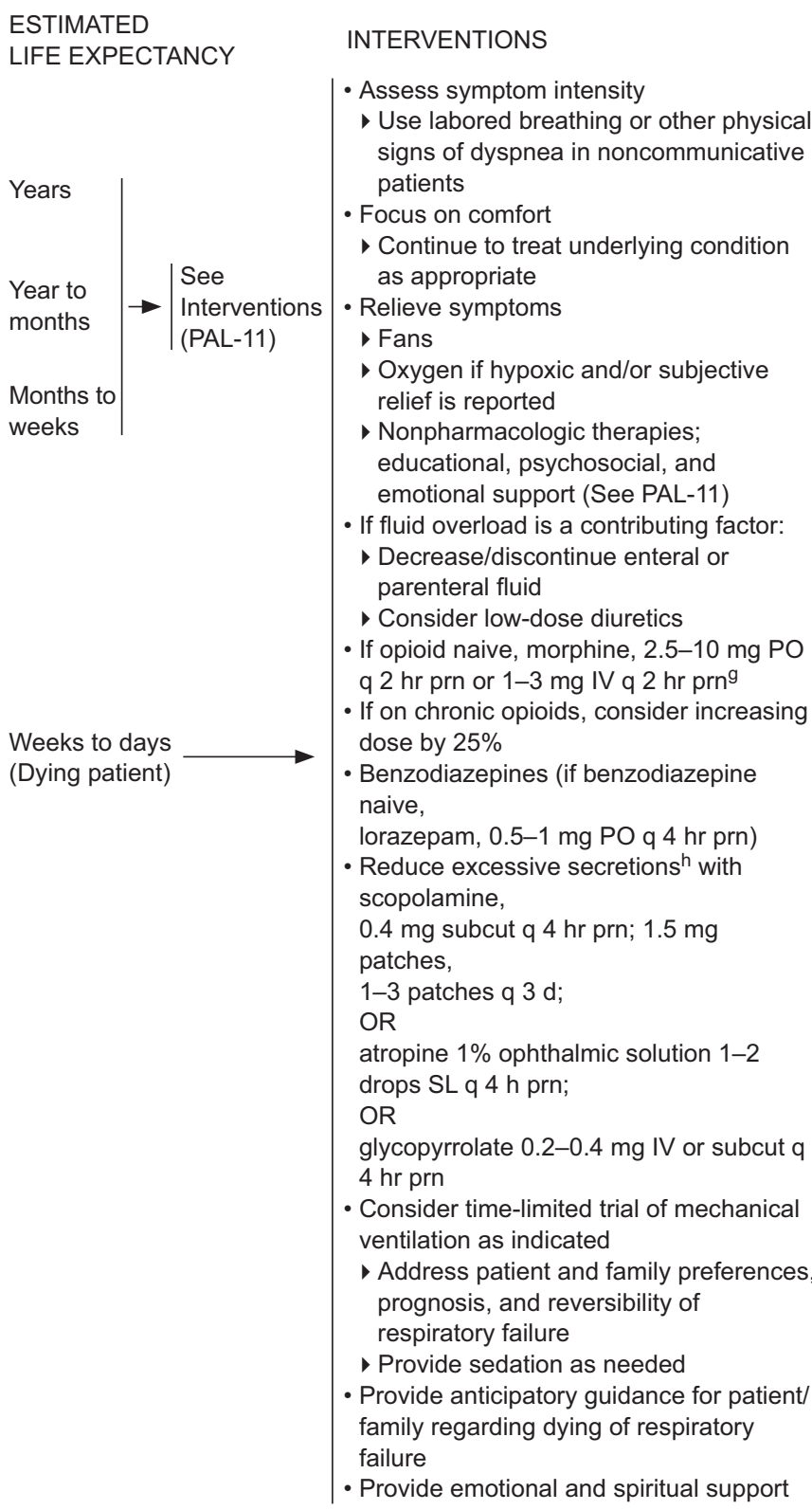

\section{REASSESSMENT}

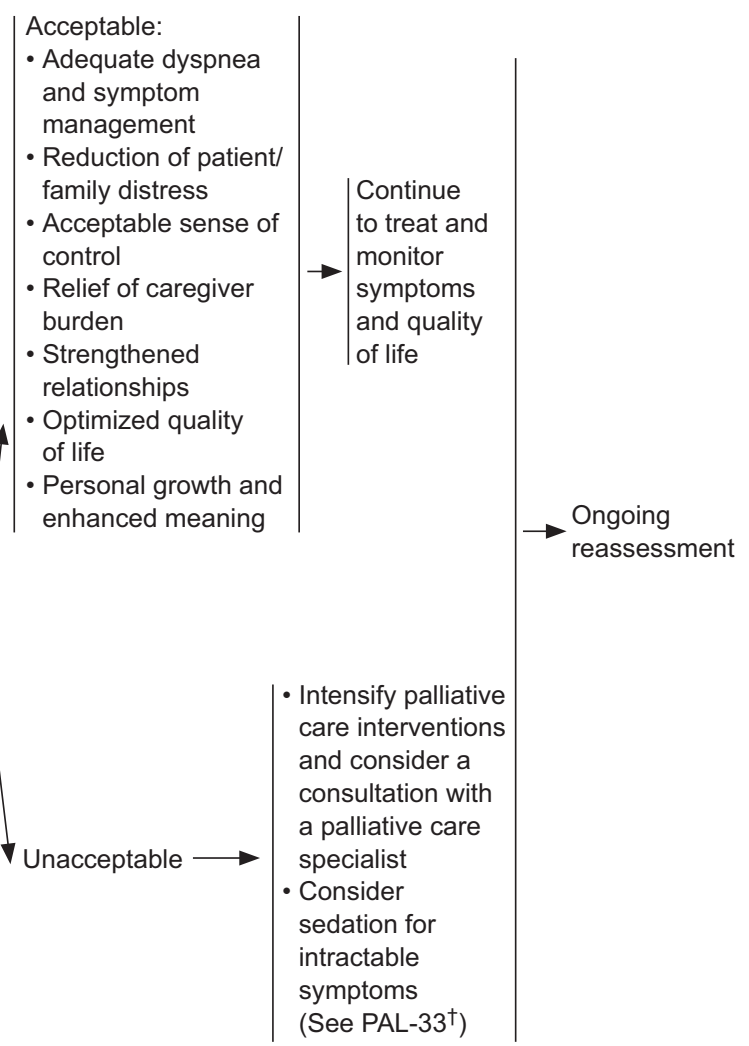

${ }^{\dagger}$ Available online, in these guideilnes, at NCCN.org.

gFor acute progressive dyspnea, more aggressive titration may be required.

hHughes A, et al. Audit of three antimuscarinic drugs for managing retained secretions. Palliative Medicine. 2000; 14:221-222.

PAL-12 


\section{ANOREXIA/CACHEXIA}

ESTIMATED

LIFE

INTERVENTIONS

EXPECTANCY

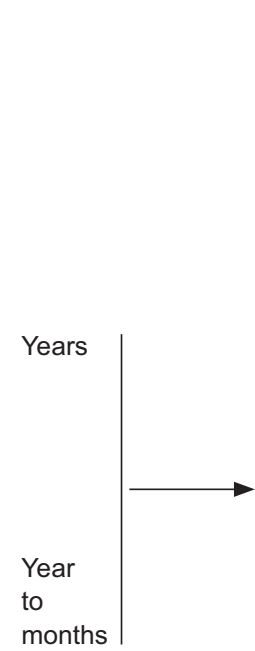

- Evaluate rate/severity of weight loss

- Treat reversible cause of anorexia:

- Oral-pharyngeal candidiasis

- Depression/anorexia

(Mirtazapine 7.5-30 mg hs)

- Symptoms that interfere with intake

- Dysgeusia

- Xerostomia

- Mucositis

- Early satiety (if gastroparesis: try metoclopramide)

- NV

- Dyspnea

- Constipation

- Pain

- Fatigue

- Eating disorders/body image

- Review/modify medications that interfere with intake

- Evaluate for endocrine abnormalities:

- Hypogonadism

- Thyroid dysfunction

- Metabolic abnormalities (eg, increased calcium)

- Consider an exercise program

- Assess social and economic factors

\begin{tabular}{l|l}
$\begin{array}{l}\text { Months to } \\
\text { weeks }\end{array}$ & $\begin{array}{l}\cdot \text { Consider nutrition consult } \\
- \text { Consider nutrition support, enteral and }\end{array}$
\end{tabular}

weeks

parenteral feeding (as appropriate)
REASSESSMENT

Acceptable:

- Weight stabilization

or gain

- Improvement in

symptoms that

interfere with intake

- Improved energy

- Resolution of

metabolic or

endocrine

abnormalities

Continue to treat and monitor symptoms and quality of life

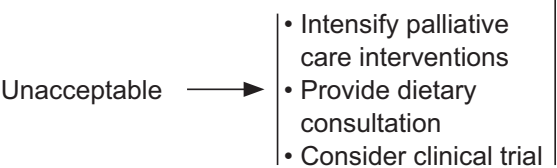

Ongoing

reassessment

Weeks to

days

(Dying

patient)

See Interventions (PAL-14)

PAL-13 
ESTIMATED

LIFE

INTERVENTIONS

EXPECTANCY

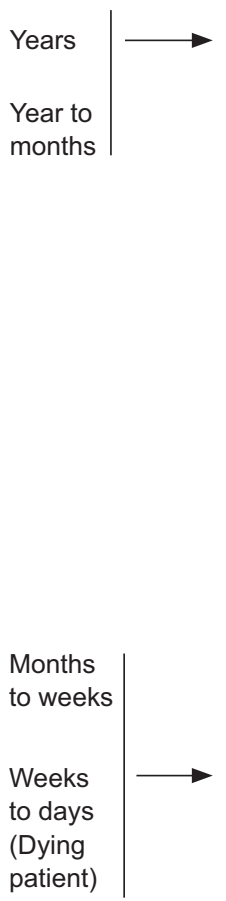

See Interventions (PAL-13)

- Assess meaning of symptoms of anorexia and cachexia to patient and family

- Consider appetite stimulant

- Megestrol acetate, 400-800 mg/d

- Olanzapine $5 \mathrm{mg} / \mathrm{d}^{\mathrm{i}}$

- Dexamethasone 2-8 mg/d

- Consider cannabinoid

- Focus on patient goals and preferences

- Provide family with alternate ways of caring for the patient

- Provide emotional support

- Treat for depression, if appropriate

(mirtazapine 7.5-30 mg hs)

- Provide education and support to patient and family regarding emotional aspects of withdrawal of nutritional support.

- Inform patient and family of natural history

of disease, including the following points:

- Absence of hunger and thirst is normal in the dying patient

- Nutritional support may not be metabolized in patients with advanced cancer

- There are risks associated with artificial nutrition and hydration, including fluid overload, infection, and hastened death

- Symptoms like dry mouth should be treated with local measures (eg, mouth care, small amounts of liquids)

- Withholding or withdrawing nutrition is ethically permissible and may improve some symptoms.

\section{REASSESSMENT}

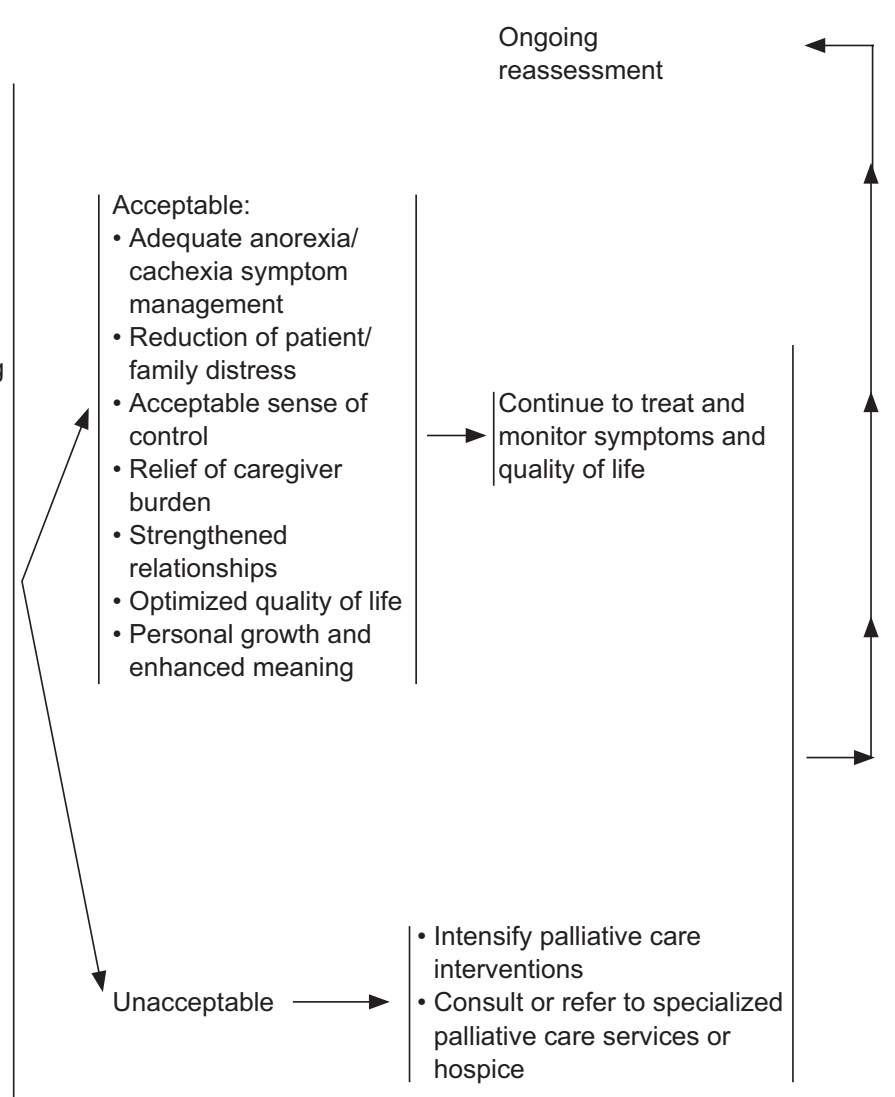

iNavari RM, Brenner MC. Treatment of cancer-related anorexia with olanzapine and megestrol acetate: a randomized trial. 2010. Support Care Cancer 18(8):951-956.

PAL-14 


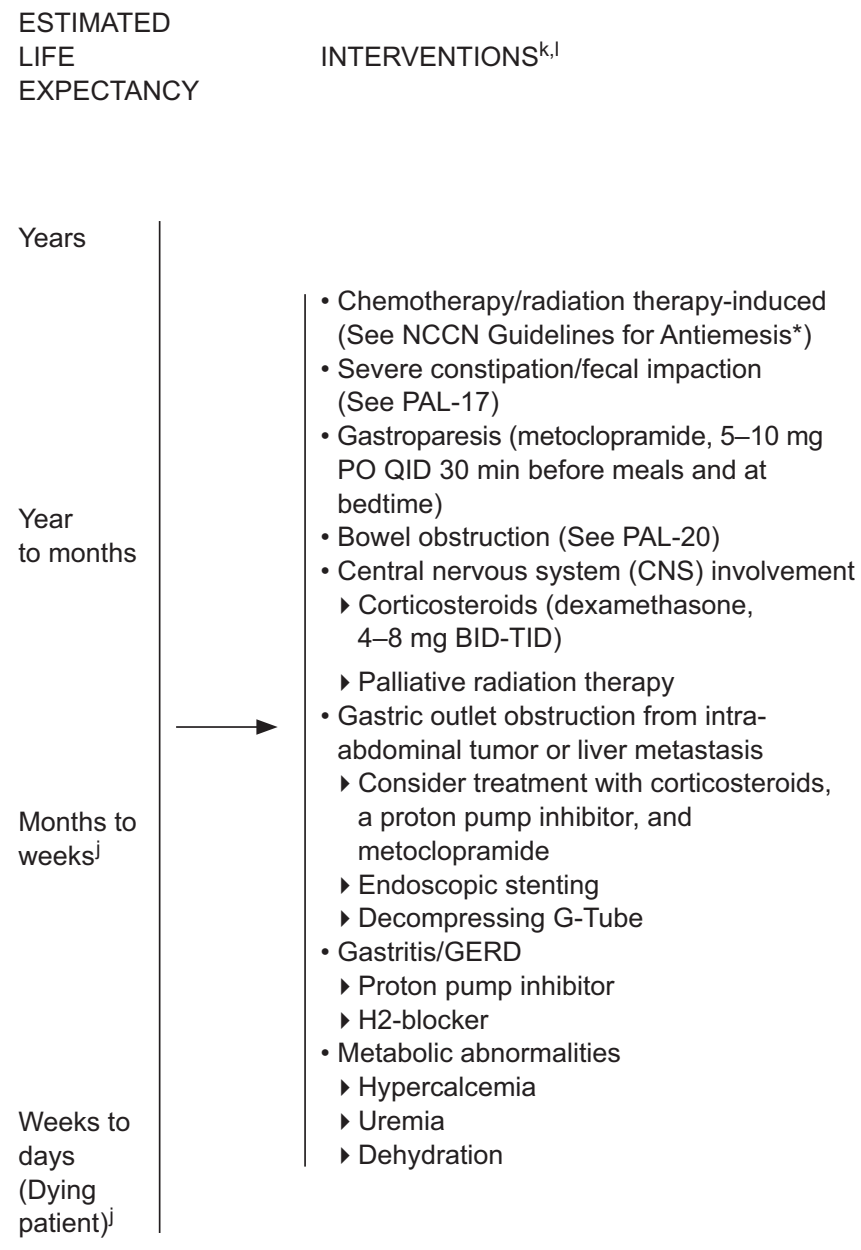

- Medication-induced

- Discontinue any unnecessary medications

- Check available blood levels of necessary medications (eg, digoxin, phenytoin, carbamazepine, tricyclic antidepressants)

- Treat medication-induced gastropathy (eg, proton pump inhibitor, metoclopramide)

- Consider rotating and/or reducing opioid requirement with nonnauseating coanalgesics or procedural interventions

- Psychogenic

- Consider psychiatric consultation if patient has an eating disorder, somatization, phobia, or panic disorder causing NV. See NCCN Guidelines for Distress Management*

- Non-specific NV

- Initiate pharmacologic management with dopamine receptor antagonists (eg, haloperidol, metoclopramide, prochlorperazine, olanzapine)

- If anxiety contributes to NV, consider adding lorazepam, 0.5-1 mg q 4 hr prn

- If oral route is not feasible, consider sublingual, rectal, subcutaneous, or intravenous administration of antinausea therapy

- Consider non-pharmacologic therapies, such as acupuncture, hypnosis, and cognitive behavioral therapy

- Consider cannabinoid

\section{If NV stops:} See Reassessment (PAL-16)

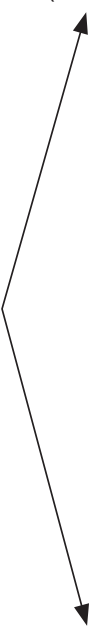

If NV persists: See Interventions (PAL-16)

*To view the most recent version of these guidelines, visit NCCN.org.

Jin patients with advanced cancer, NV may be secondary to the cachexia syndrome (chronic nausea, anorexia, asthenia, changing body image, and autonomic failure).

kAn around-the-clock dosing schedule may provide the most consistent benefit to the patient.

IContinuous intravenous or subcutaneous infusions of different antiemetics may be necessary for the management of intractable NV.

PAL-15 


\section{INTERVENTIONS}

Titrate dopamine receptor antagonist (eg, prochlorperazine, haloperidol, metoclopramide, olanzapine) to maximum benefit and tolerance.

If NV persists:<smiles>[3H][V]</smiles>

Add a 5-HT3 antagonist (eg, ondansetron) \pm anticholinergic agent (eg, scopolamine) \pm antihistamine (eg, meclizine)

\pm cannabinoid.

If NV persists:

Add a corticosteroid (eg, dexamethasone) \pm olanzapine, if not already tried. If $\mathrm{NV}$ persists:

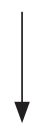

Consider using a continuous IV/subcut infusion of antiemetics; consider an opioid rotation if patient is on opioids.

\section{REASSESSMENT}

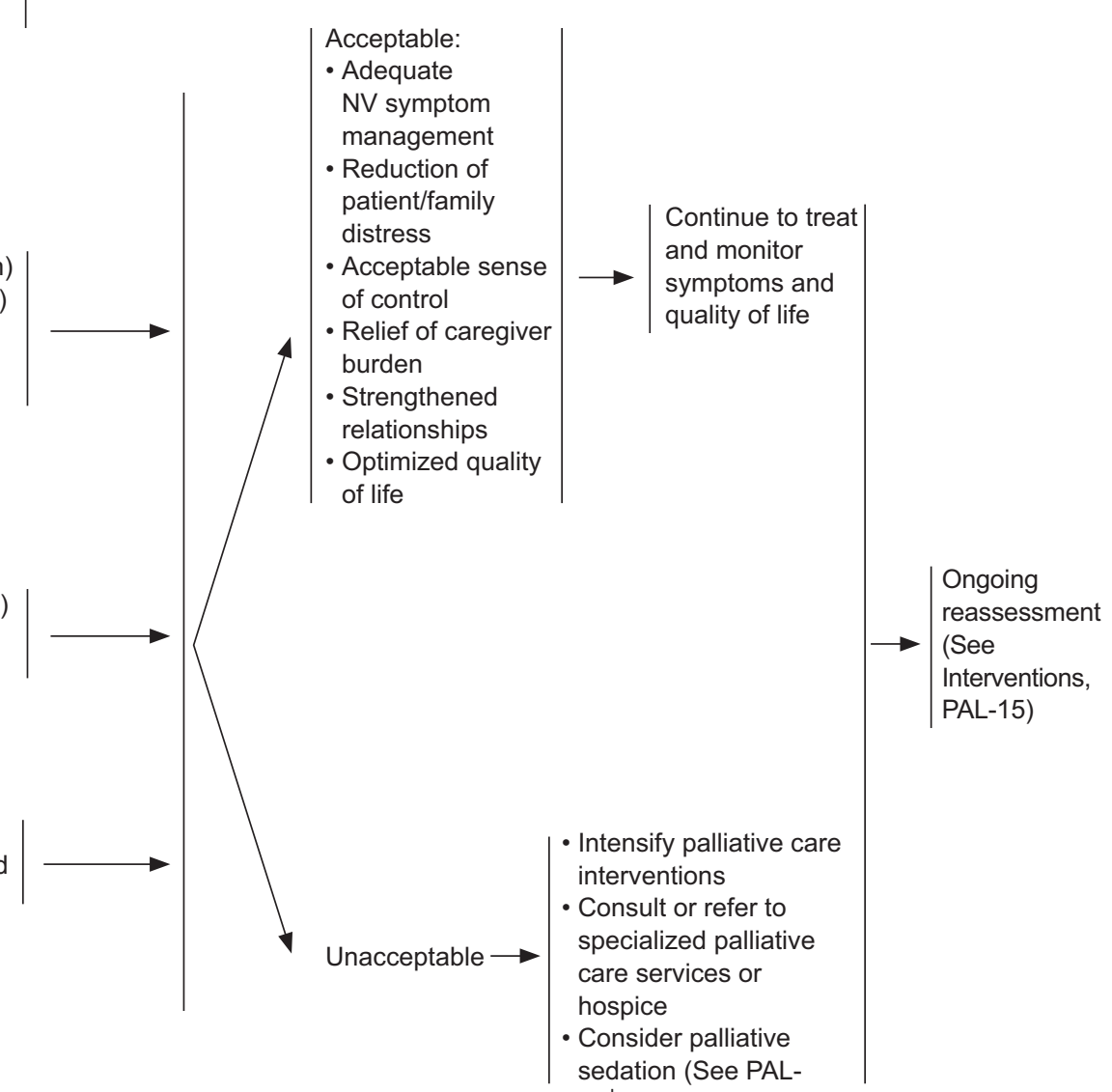

$33^{\dagger}$ )

${ }^{\dagger}$ Available online, in these guidelines, at NCCN.org.

PAL-16 


\section{CONSTIPATION}

\section{ESTIMATED}

LIFE

EXPECTANCY

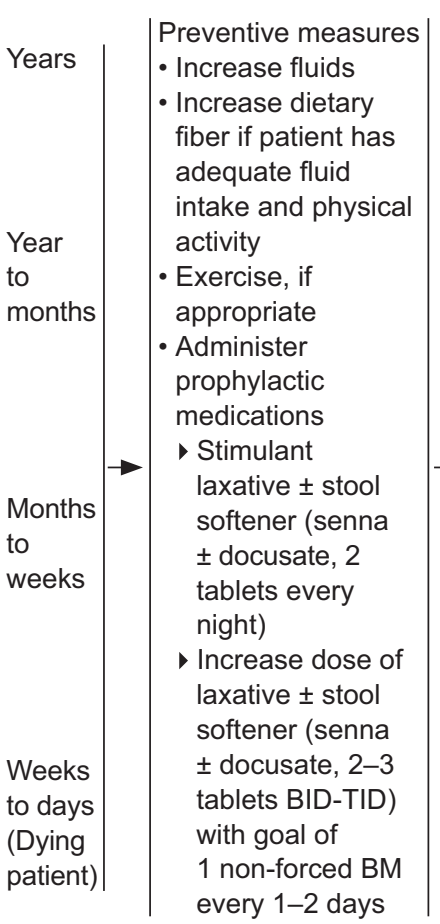
movement (BM) every 1-2 days

\section{INTERVENTIONS}

If constipation is present:

- Assess for cause and severity of constipation

- Discontinue any non-essential constipating medication

- Rule out impaction, especially if diarrhea accompanies constipation (overflow around impaction)

- Rule out obstruction (physical exam, abdominal x-ray/consider GI consult)

- Treat other causes (eg, hypercalcemia, hypokalemia, hypothyroidism, diabetes mellitus, medications)

- Add and titrate bisacodyl 10-15 mg dailyTID with a goal of 1 non-forced bowel

If impacted:

- Administer glycerine suppository \pm mineral oil retention enema

- Perform manual disimpaction following pre-medication with analgesic \pm anxiolytic If constipation persists:

- Reassess for cause and severity of constipation

- Recheck for impaction or obstruction

- Consider adding other laxatives, such as bisacodyl suppository (one rectally dailyBID); polyethelene glycol (1 capful/8 oz water BID); lactulose, 30-60 mL BID-QID; sorbitol, $30 \mathrm{~mL}$ every $2 \mathrm{~h} \times 3$, then prn; magnesium hydroxide, $30-60 \mathrm{~mL}$ daily-BID; or magnesium citrate, 8 oz daily

- Consider methylnaltrexone for opioidinduced constipation, except for post-op ileus and mechanical bowel obstruction, $0.15 \mathrm{mg} / \mathrm{kg} \mathrm{SC}$ subcut every other day, no more than once a day

- Tap water enema until clear

- Consider use of a prokinetic agent (eg,

metoclopramide, 10-20 mg PO QID)

\section{REASSESSMENT}

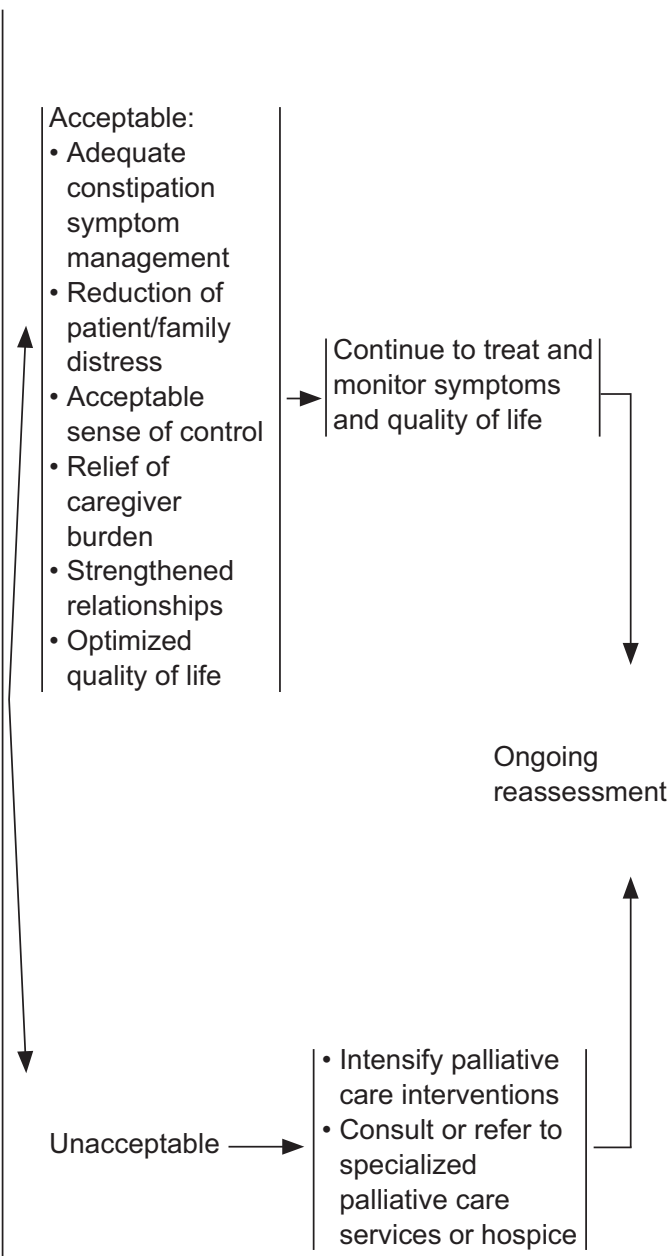




\section{DIARRHEA}

ESTIMATED

LIFE

EXPECTANCY

Years

Year

to

months

Months

to

weeks

\section{SCREENING}

Determine Diarrhea Grade ${ }^{m}$ (Increase over Baseline)

- Grade 1: Increase of <4 stools/day over baseline; mild increase in ostomy output compared with baseline

- Grade 2: Increase of 4-6 stools/day over baseline; moderate increase in ostomy output compared with baseline

- Grade 3: Increase of $>7$ stools/day over baseline; incontinence; hospitalization indicated; severe increase in ostomy output compared with baseline; limiting self-care; Interferes with ADL

- Grade 4: Life-threatening consequences urgent intervention indicated

\section{ASSESSMENT}

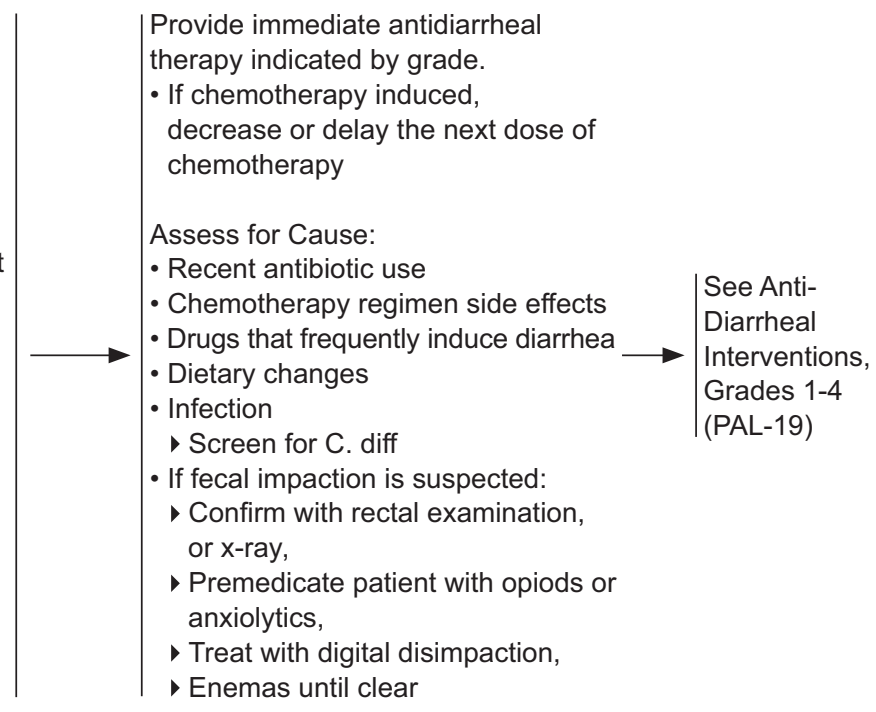

Weeks to days

(Dying patient)

See PAL-19

mNCl Tahle. 3. httn//www cancer anv/cancertonics/nda/sunnortivecare/aastrointestinalcomnlications/HealthProfessional/nage5\#section 5 8 


\section{ESTIMATED \\ LIFE \\ EXPECTANCY}

Years

Year

to

months

\section{ANTIDIARRHEAL INTERVENTIONS}

SCREENING

\section{INTERVENTION}

- Provide oral hydration and electrolyte replacement

- Initiate antidiarrheal:

- Loperamide $4 \mathrm{mg}$ PO x 1, then 2 mg PO after each loose stool, up to 16 mg/day

- If patient not already on opioids:

- Diphenoxylate/atropine 1-2 tabs PO q 6 hr PRN, Maximum 8 tabs/day

- Bland/BRAT diet (Bananas, Rice, Applesauce, Toast)

- Continue oral hydration and electrolyte replacement

- If chemotherapy-induced:

- Decrease dose or discontinue chemotherapy

- Provide IV fluids if patient is unable to tolerate oral fluids

- Initiate/continue antidiarrheal--as above

- Bland/BRAT diet (Bananas, Rice, Applesauce, Toast)

- Continue oral hydration and electrolyte replacement

- Consider anticholinergic agents

- Hyoscyamine 0.125 mg PO/ODT/SL q 4 hr PRN, Max: 1.5 mg/day

- Atropine 0.5-1 mg subcut; IM; IV; SL q 4-6 hr prn

- If infection-induced (C. diff):

GRADE $2 \longrightarrow$ Metronidazole 500 mg PO/IV QID x 10-14 days

- Vancomycin 125-500 mg PO QID x 10-14 days

- If infection-induced and not C.diff

- Treat with appropriate antibiotics

- If chemotherapy-induced:

- Delay or discontinue chemotherapy

- If ipilimumab-related diarrhea, consider

- Corticosteroids for $0.1-1 \mathrm{mg} / \mathrm{kg} / \mathrm{day}$

- Infliximab 5 mg/kg q 2-6 weeks

Persistent $\quad$ Inpatient hospitalization (intensive care for Grade 4)

GRADES 2, 3, $4 \longrightarrow$ - Provide IV fluids and use antidiarrheal agents and anticholinergics as mentioned above

- Consider Octreotide 100-500 mcg/day subcut or IV, q 8 hr or by continuous infusion

- Ensure that the above interventions are consistent with the goals of care

- Consider IV hydration at home

- Start on around the clock opioids or increase dose of current opioid

- Consider Scopolamine 0.4 mg subcut every 4 hrs prn

- Consider Octreotide 100-200 microgram subcut q 8 hrs

- Consider glycopyrrolate 0.2-0.4 mg IV q 4 hr prn

PAL-19 


\section{MALIGNANT BOWEL OBSTRUCTION ${ }^{n}$}

\section{ESTIMATED}

LIFE

ASSESSMENT

EXPECTANCY
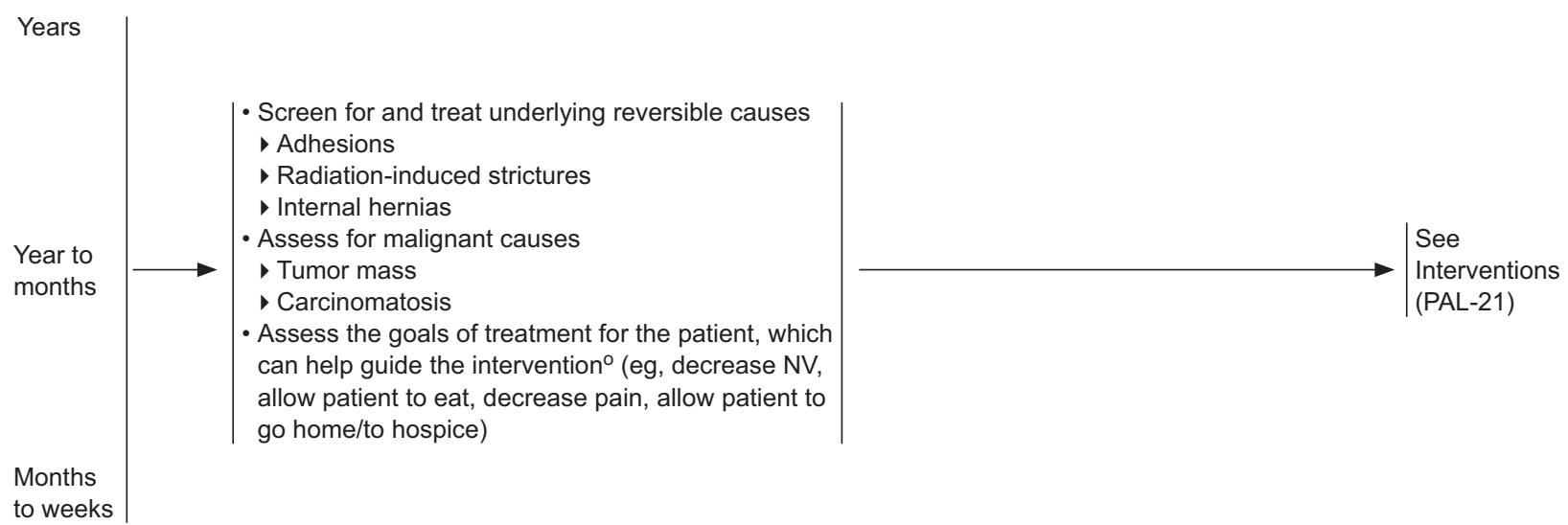

to weeks

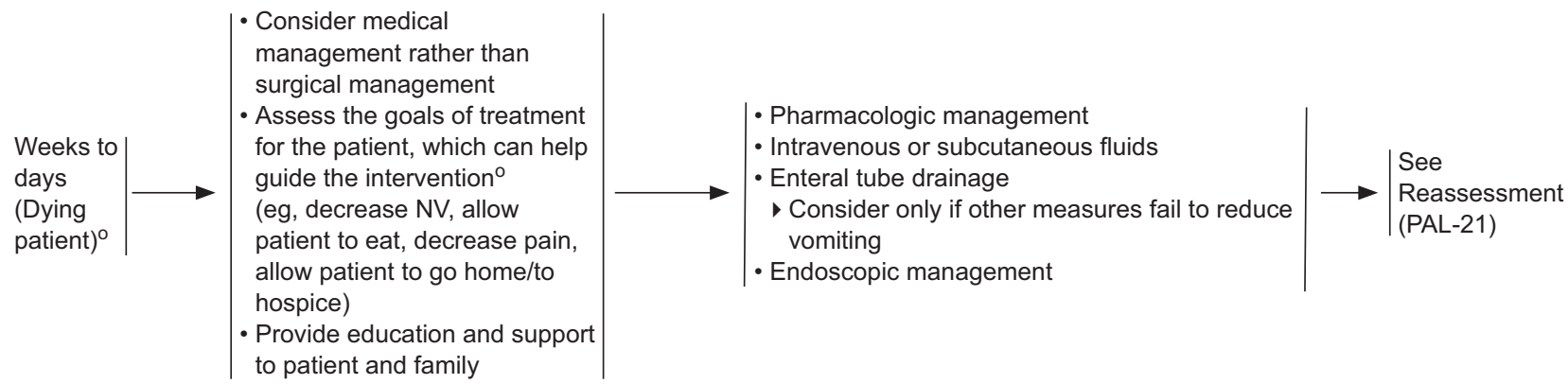

nPlain film radiography may be helpful in confirming the clinical diagnosis of bowel obstruction. Consider a computed tomography scan if surgical intervention is contemplated, as it is more sensitive and may help identify the cause of obstruction.

oMost malignant bowel obstructions are partial, allowing time to discuss appropriate intervention with the patient and family.

PAL-20

Version 1.2016, 11-17-15 @2015 National Comprehensive Cancer Network, Inc. All rights reserved. The NCCN Guidelines ${ }^{\circledR}$ and this illustration may not be reproduced in any form without the express written permission of $\mathrm{NCCN}^{\circledR}$. 


\section{INTERVENTIONS}

- Operative management

- Risks must be discussed with the patient/family ${ }^{p}$

- Improved quality of life should be the primary goal of surgical treatment

- Endoscopic management

- Percutaneous endoscopic gastrostomy tube for drainage

- Endoscopic stent placement

- Interventional radiology management

- Ultrasound-guided gastrostomy tube for drainage

- Pharmacologic management when the goal is maintaining gut function:

- Use rectal, transdermal, subcutaneous, or intravenous routes of administration

- Opioids

- Antiemetics: Do not use antiemetics that increase gastrointestinal mobility such as metoclopramide; however, these may be beneficial in incomplete bowel obstruction

- Corticosteroids: Dexamethasone 4-12 mg IV, daily, discontinue if no improvement in 3-5 days

- Pharmacologic management when gut function cannot be maintained:

- Administer anticholinergics (eg, scopolamine, hyoscyamine, glycopyrrolate)

- Administer octreotide: (100-300 mcg SC BID-TID or 10-40 $\mathrm{mcg} / \mathrm{hr}$ continuous SC/IV infusion) if prognosis $>8$ weeks, consider long acting release (LAR) or depot injection

- Intravenous or subcutaneous fluids

- Consider if there is evidence of dehydration

- Nasogastric or gastric tube drainage

- Usually uncomfortable

- Increased risk of aspiration

- Consider a limited trial only if other measures fail to reduce vomiting

- Total parenteral nutrition (TPN)

- Consider only if there is expected improvement of quality of life and life expectancy of months to years

\section{REASSESSMENT}

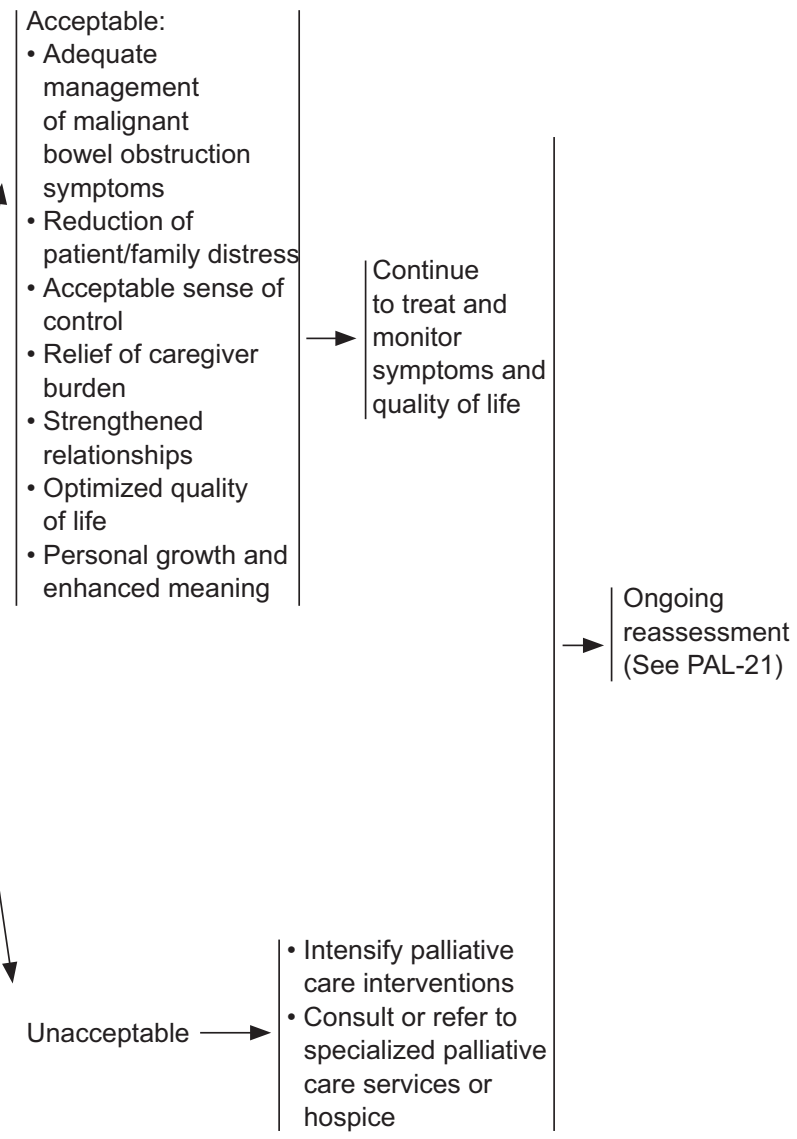




\section{SLEEP/WAKE DISTURBANCES INCLUDING INSOMNIAAND SEDATION}

\section{INTERVENTIONS}

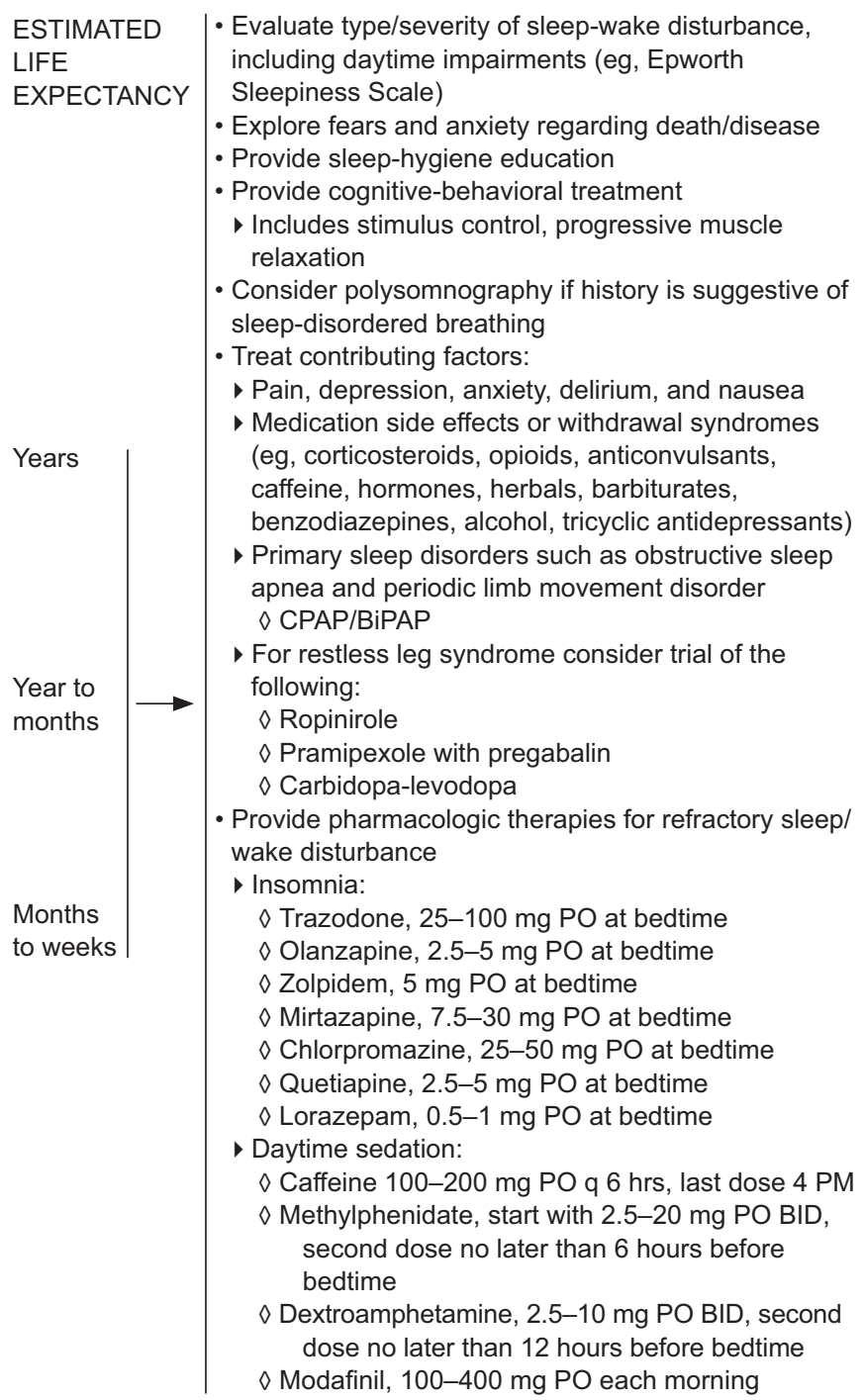

Weeks
to days
$\begin{aligned} & \text { (Dying } \\ & \text { patient) }\end{aligned}$$\longrightarrow \longrightarrow \begin{aligned} & \cdot \text { Assess patient's desire to have insomnia and sedation } \\ & \text { treated } \\ & \begin{array}{l}\text { Adjust doses of pharmacologic therapies } \\ \text { Consider chlorpromazine, 25-100 mg PO/PR at } \\ \text { bedtime }\end{array}\end{aligned}$

\section{REASSESSMENT}

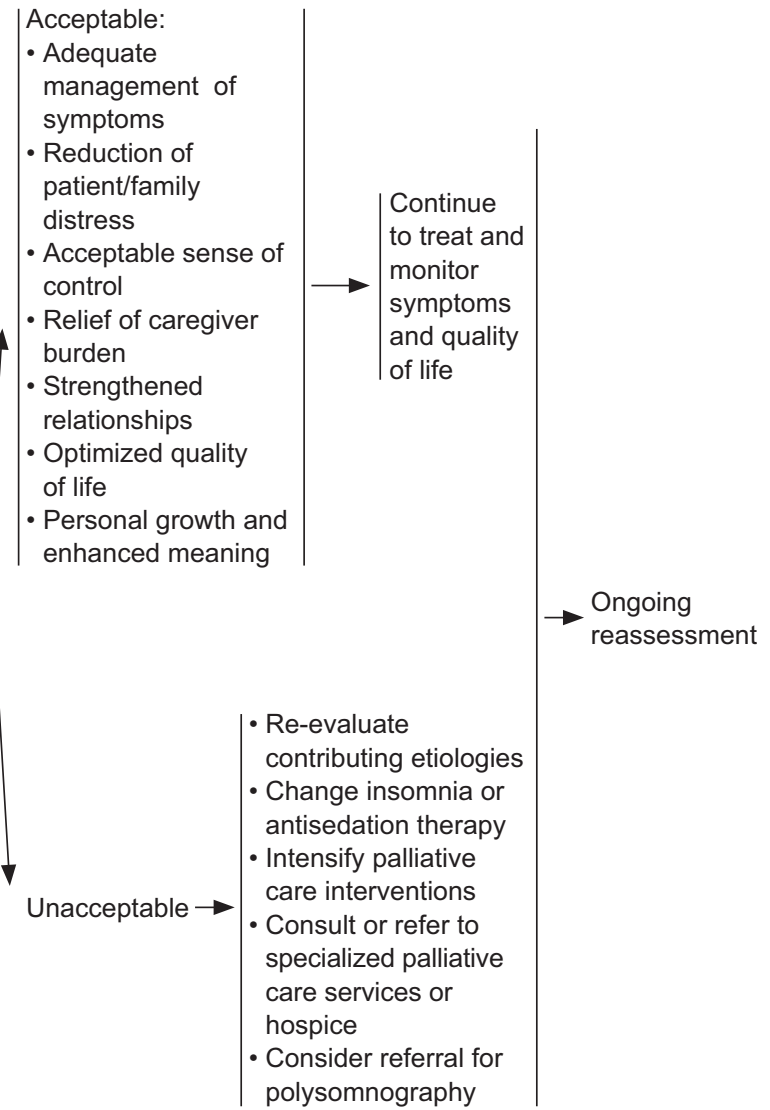


assessment by their primary oncology team, evaluating the benefits and burdens of anticancer therapy; physical symptoms; psychosocial or spiritual distress; personal goals, values, and expectations; educational and informational needs; and cultural factors affecting care. ${ }^{1-3}$

\section{Assessment for Benefits and Burdens of Anticancer Therapy}

Many cancer symptoms can be relieved by controlling the cancer with anti-cancer therapy. Assessment of the benefits and burdens of anticancer therapy for each individual is based on the existing NCCN disease-specific guidelines (the most recent version of all guidelines can be found on the NCCN Web site at NCCN.org). Special attention should be given to the natural history of the specific tumor; the potential for response to further treatment; the meaning of anticancer therapy to the patient and family; the potential for treatment-related toxicities, including impairment of vital organs and performance status; and serious comorbid conditions. Specific recommendations regarding anticancer therapy for patients with various life expectancies are discussed in Palliative Care Interventions (see next column).

\section{Assessment of Personal Goals, Values, and Expectations}

Patients and families should also be asked about personal goals, values, and expectations. Their priorities for palliative care, including their goals and the perceived meaning of anticancer therapy and the importance they place on quality of life, should be assessed. Goals and expectations that might be better met by the hospice model of palliative care should be identified. When appropriate, it is important to determine the patient's understanding of the incurability of their disease and whether patients wish to know survival statistics.

\section{Assessment of Physical Symptoms}

The most common symptoms that need to be assessed are pain, dyspnea, anorexia, cachexia, nausea, vomiting, constipation, malignant bowel obstruction, fatigue, weakness, asthenia, insomnia, daytime sedation, and delirium. ${ }^{4}$ Palliative interventions for these symptoms are discussed individually in subsequent sections.

\section{Assessment of Psychosocial Distress}

Assessment of psychosocial distress should focus on illness-related distress and psychosocial, spiritual, or existential issues according to the NCCN Guidelines for Distress Management (available at NCCN.org). Special problems with social support and resources (ie, home, family, community, or financial issues) must also be assessed. Recommendations for the management of psychosocial distress can be found in subsequent sections and in the NCCN Guidelines for Distress Management (available at NCCN.org).

\section{Assessment of Educational and Informational Needs and Cultural Factors Affecting Care}

The values and preferences of patients and families about information and communication should also be assessed. The oncology team should inquire about cultural factors affecting care and perceptions of the patient/family regarding the patient's disease status.

\section{Palliative Care Interventions}

The oncology team should start palliative treatments following the specific recommendations described in these guidelines for common symptoms. Comorbid physical and psychosocial conditions should be treated by appropriate clinicians. Consultation or collaboration with palliative care specialists or teams is recommended for patients with more complex problems to improve their quality of life and survival. ${ }^{5,6}$ Referrals should be made as needed to mental health and social services, pastoral care, health care interpreters, hospice services, or other specialists. Finally, the oncology team can be helpful in mobilizing community support through religious organizations, schools, or community agencies.

The panel divided patients into 3 groups to address the effect of life expectancy on the delivery of palliative care interventions: 1 ) patients with years to months to live; 2) patients with months to weeks to live; and 3) dying patients in their final weeks to days. Patients in their final hours of life are referred to as "imminently dying" and may require special interventions. The panel recognizes the lack of precision in estimating life expectancy but believes that this delineation will be useful for the delivery of appropriate palliative care interventions. The patient and family's personal, spiritual and existential, cultural, and religious goals, values, and expectations may change throughout these timeframes. Optimal provision of palliative care requires ongoing reassessment and modification of strategies, as well as ongoing communication between the patient, family, and health care team. 
Indicators that patients are in their last 6 months of life include decreased performance status (ECOG score $\geq 3$; Karnofsky Performance Score $\leq 50$ ), persistent hypercalcemia, central nervous system metastases, delirium, superior vena cava syndrome, spinal cord compression, cachexia, malignant effusions, liver failure, kidney failure, or other serious comorbid conditions. Many patients with stage IV cancers, especially those with metastatic lung cancer, pancreatic cancer, and glioblastoma multiforme, would benefit from palliative care beginning at diagnosis, because expected survival is limited. ${ }^{7-9}$

\section{Anticancer Therapy}

A recent Institute of Medicine (IOM) report, "Communicating with Patients on Health Care Evidence," found that $90 \%$ of Americans surveyed want to know their options for tests and treatments and to be involved in decision-making for their health, with almost $50 \%$ wanting to discuss the option of doing nothing. ${ }^{10,11}$ However, the report also found that far fewer respondents had such discussions with their physicians.

Patients who have years to months to live and a good performance status are likely to be interested in continuing anticancer therapy to prolong survival and reduce cancer-related symptoms. ${ }^{12-15}$ Anticancer therapy may be conventional evidence-based treatment as outlined in the NCCN disease-specific guidelines (available at NCCN.org) or treatment in the context of a clinical trial. In some of the advanced-stage cancers, chemotherapy may be superior to best supportive care and may prolong survival. ${ }^{16,17}$ Furthermore, patients with advanced non-small cell lung cancer who are not eligible for systemic chemotherapy may benefit from targeted therapies that are effective for relieving symptoms, maintaining stable disease, and improving quality of life without the adverse events that may be associated with cytotoxic cancer therapies. ${ }^{18}$ Physicians, patients, and their families should discuss intent, goals, and range of choices; benefits and burdens of anticancer therapy; and possible effects on quality of life. In addition, the oncology team should prepare the patient psychologically for possible disease progression.

Anticancer therapy may at times go beyond what is evidence-based. Interestingly, data from a CanCORS study of 1574 patients with metastatic non-small cell lung cancer suggested that many patients received higher doses and a greater number of palliative radiation treatments than is supported by current evidence. ${ }^{19}$ Additionally, a study of patients with metastatic colorectal cancer revealed that more than $90 \%$ of patients consulted with a medical oncologist, and $82 \%$ of these patients received chemotherapy. ${ }^{20}$

Patients with months to weeks to live should be provided with guidance regarding the anticipated course of the disease. Physicians should confirm patient understanding of goals of therapy and preferences regarding prognostic information. Patients at this point are typically tired of therapy, homebound, and concerned about the side effects of more treatment. The focus of treatment for these patients shifts from prolonging life toward maintaining quality of life. These patients should consider potential discontinuation of anticancer treatment and be offered best supportive care, including referral to palliative care or hospice..$^{21,22}$ To avoid demeaning the value of end-of-life care, palliative care and/or hospice care should not be described as "giving up," but instead reframed as "fighting" for better quality of life.

In general, patients with weeks to days to live (ie, dying patients) should not be given anticancer therapy but should be given intensive palliative care focusing on symptom management and preparation for the dying process.

\section{Symptom Management}

Special considerations in the implementation of these guidelines based on life expectancy are delineated in the algorithms (see page 84). The major focus of these special considerations is the withholding and withdrawal of aggressive interventions; prevention and elimination of side effects associated with pharmacologic pain management; the acceptance of loss of function for the sake of relief of symptoms; and the treatment of the unique symptoms of patients in their final hours of life.

With regard to symptoms, the management of pain, dyspnea, anorexia/cachexia, nausea and vomiting, constipation, diarrhea, malignant bowel obstruction, fatigue, delirium, and psychologic distress is fundamental. ${ }^{23-25}$ These symptoms are discussed in detail in subsequent sections. As a general principle, if/when appropriate, providers should try to use palliative interventions that may address multiple symptoms.

Pain: See the NCCN Guidelines for Adult Cancer Pain (available online at NCCN.org) for more de- 
tail. In addition, it is important to note that dying patients in their last weeks of life have several specific requirements. For instance, opioid dose should not be reduced solely for decreased blood pressure, respiration rate, or level of consciousness when opioid is necessary for adequate management of dyspnea and pain. In fact, opioids can be titrated aggressively for moderate/severe acute/chronic pain. ${ }^{26}$ In addition, palliative sedation can be considered for refractory pain (see next section) after consultation with pain management/palliative care specialists.

Dyspnea: Dyspnea is one of the most common symptoms in patients with advanced lung cancer. ${ }^{27}$ The American Thoracic Society consensus statement defines dyspnea as "a subjective experience of breathing discomfort that consists of qualitatively distinct sensations that vary in intensity." 28

Symptom intensity should first be assessed in all patients. Symptom intensity in noncommunicative patients with weeks to days to live should be assessed using physical signs of dyspnea. Underlying causes or comorbid conditions should then be treated using chemotherapy or radiation therapy; therapeutic procedures for cardiac, pleural, or abdominal fluid; ${ }^{29-31}$ bronchoscopic therapy; or bronchodilators, diuretics, steroids, antibiotics, transfusions, or anticoagulants for pulmonary emboli.

Both pharmacologic and nonpharmacologic interventions have been investigated in the management of dyspnea. A recent review concluded that little definitive data evaluating the effectiveness of dyspnea interventions exist and that randomized controlled trials are needed.32 Other reviews have determined that there are sufficient data to make treatment recommendations..$^{30,33}$ Pharmacologic interventions may include opioids with or without benzodiazepines. ${ }^{30,34-39}$ Benzodiazepines can be tried for treatment of dyspnea if it is associated with anxiety; the beneficial effect of benzodiazepines on dyspnea in patients with advanced cancer is small. ${ }^{39}$

Of the opioids, morphine has undergone the most extensive investigation for treating dyspnea in patients with cancer, but recent studies have also looked at opioids such as fentanyl and oxycodone. A single-institution trial of nebulized fentanyl in patients with cancer with dyspnea showed improved oxygenation and reduced tachypnea, and 79\% of patients said it improved their breathing. ${ }^{40}$ An attempted randomized, placebo-controlled trial at the same institution was not successful, because the practice had already diffused widely, with more than 1000 doses being prescribed. ${ }^{41}$

Multiple case reports show promising data about fentanyl, but further research is needed. ${ }^{42}$ In a small, randomized controlled trial, prophylactic subcutaneous fentanyl was effective for improving dyspnea and fatigue at rest and after a 6 -minute walk test. ${ }^{43} \mathrm{~A}$ study revealed that nebulized fentanyl reduced intensity and unpleasantness of dyspnea in patients with chronic obstructive pulmonary disease (COPD). ${ }^{44}$ Nebulized fentanyl has not yet been studied in patients with cancer, but it can be considered in patients who do not respond well to the other interventions in these guidelines. Additionally, an observational study of 136 patients with terminal cancer also suggested that continuous infusion of subcutaneous oxycodone may provide relief of dyspnea in addition to relief of pain. ${ }^{45}$ For patients receiving chronic opioids, the panel recommends consideration of a $25 \%$ dose increase to manage dyspnea.

Scopolamine, atropine, hyoscyamine, and glycopyrrolate are options to reduce excessive secretions associated with dyspnea. ${ }^{46-50}$ Glycopyrrolate does not effectively cross the blood brain barrier and is less likely than the other drug options to cause delirium, but this agent can produce anticholinergic side effects. ${ }^{51-53}$ Scopolamine can be administered subcutaneously or transdermally; physicians should be aware that the onset of benefit for transdermal scopolamine patches is about 12 hours, ${ }^{54}$ and they are thus not an appropriate choice for imminently dying patients. A subcutaneous injection of scopolamine can be administered when the patch is applied or if management of secretions is inadequate.

Nonpharmacologic interventions include the use of handheld fans directed at the face, supplemental oxygen, and mechanical ventilation. A randomized, controlled, crossover trial demonstrated that breathlessness was reduced in patients when they directed a handheld fan toward their faces. ${ }^{55}$ Another randomized controlled trial examined the effects of room air versus palliative oxygen delivered via nasal cannula in patients with refractory dyspnea. Dyspnea scores were no different among patients receiving palliative oxygen versus room air, encouraging the use of less burdensome interventions. ${ }^{56}$ In a recent feasibility study of 200 patients with solid tumors randomized to receive either noninvasive positive-pressure ven- 
tilation (biphasic positive airway pressure, BiPAP) or oxygen therapy, patients in the ventilation group had greater improvements in dyspnea symptoms and required lower doses of opiates than patients in the oxygen group. ${ }^{57}$ However, a smaller phase II randomized trial comparing high-flow oxygen to BiPAP for persistent dyspnea in patients with advanced cancer revealed no significant differences between the two approaches. ${ }^{58}$

A time-limited trial of mechanical ventilation, as clinically indicated, and/or oxygen therapy for hypoxia may be beneficial. High-flow nasal oxygen and BiPAP may temporarily improve hypoxemia, but these are never available outside the hospital setting. As life expectancy decreases, the role of mechanical ventilation and oxygen diminishes and the role of opioids, benzodiazepines, glycopyrrolate, and scopolamine increases. If fluid overload is a contributing factor, enteral and parenteral fluids should be decreased or discontinued, and low-dose diuretics can be considered.

Anorexia/Cachexia Cachexia is physical wasting with loss of skeletal and visceral muscle mass and is very common among patients with cancer. ${ }^{59,60}$ Many patients with cancer lose the desire to eat (anorexia), which contributes to cachexia. Cachexia can also occur independently from anorexia, as proinflammatory cytokines and tumor-derived factors directly lead to muscle proteolysis. ${ }^{59,60}$ Cachexia leads to asthenia (weakness), hypoalbuminemia, emaciation, immune system impairment, metabolic dysfunction, and autonomic failure. Cancer-related cachexia has also been associated with failure of anticancer treatment, increased treatment toxicity, delayed treatment initiation, early treatment termination, shorter survival, and psychosocial distress. ${ }^{59-61}$ A recent study that examined cancer cachexia in a cohort of 1473 patients across all weight ranges showed that muscle depletion conveys a similarly poor prognosis as involuntary weight loss, regardless of body mass index. ${ }^{62}$

Reversible causes of anorexia, such as oropharyngeal candidiasis and depression, should be addressed. Treatment includes the relief of symptoms that interfere with food intake (eg, pain, constipation, nausea/vomiting), as well as metoclopramide for early satiety. ${ }^{30,33}$

For patients with months-to-weeks or weeks-todays life expectancy, consider the use of appetite stimulants (eg, megestrol acetate, dexamethasone, olan- zapine) if increased appetite is an important aspect of quality of life. ${ }^{63-67} \mathrm{~A}$ recent systematic review and meta-analysis of megestrol acetate revealed improved appetite and slight improvements in weight gain when using this drug to treat anorexia/cachexia in patients with cancer. ${ }^{64}$ Although 1 of 4 patients treated with megestrol acetate will have an increase in appetite and 1 of 12 will have an increase in weight, clinicians need to know that 1 of 6 will develop thromboembolic phenomena and 1 of 23 will die. ${ }^{64}$

A combination therapy approach may yield the best possible outcomes for patients with cancer cachexia. A randomized phase III trial in 332 patients with cancer-related anorexia/cachexia revealed superior outcomes for patients receiving a combination regimen that included medroxyprogesterone, megestrol acetate, eicosapentaenoic acid and L-carnitine supplementation, and thalidomide, versus therapy with any of the previously discussed single agents. ${ }^{68}$ Another phase III trial of 104 patients with advanced gynecologic cancers and cachexia supported the merits of combination therapy; compared with megestrol acetate alone, patients receiving megestrol acetate plus L-carnitine, celecoxib, and antioxidants had improved lean body mass, appetite, and quality of life. ${ }^{69}$

Although cannabinoid-based interventions (eg, dronabinol, cannabis) have some demonstrated efficacy for treating chemotherapy-induced nausea and vomiting and AIDS-related anorexia, the data to support cannabinoid-based interventions for treating anorexia/cachexia in patients with cancer are very limited. ${ }^{70} \mathrm{~A}$ randomized clinical trial of cannabis extract and delta-9-tetrahydrocannabinol in patients with cancer-related anorexia-cachexia syndrome did not demonstrate a benefit of these agents over placebo on appetite and quality of life. ${ }^{71} \mathrm{An}$ other randomized trial comparing megestrol acetate to dronabinol in treating cancer-associated anorexia revealed megestrol acetate to be superior for promoting weight gain ( $75 \%$ vs $49 \%$ of patients) and appetite $(11 \%$ vs $3 \%)$ in patients with advanced cancer. ${ }^{72}$ However, to a lesser extent, dronabinol did improve appetite and weight gain in some study patients. Ultimately, for some patients with cancer-related anorexia, cannabinoids could be helpful. However, it is important to note that cannabinoid administration in elderly patients may induce delirium, and providers should be aware of the local state rules and regu- 
lations regarding medicinal cannabinoid use.

Nutrition consultation should also be considered, because calorie-dense, high-protein supplementation has demonstrated some efficacy for weight stabilization, ${ }^{30,59,73-75}$ although some studies show nutritional interventions to be ineffective. ${ }^{76} \mathrm{~A}$ meta-analysis found that although nutritional intervention does not significantly affect weight gain or energy intake, it can improve some aspects of quality of life, including emotional functioning, dyspnea, and hunger. ${ }^{77}$ Nutritional support, including enteral and parenteral feeding as appropriate, should also be considered when the disease or treatment affects the ability to eat and/or absorb nutrients and the patient's life expectancy is months to years. ${ }^{78}$ The goals and intensity of nutritional support change as life expectancy is reduced to weeks to days. Overly aggressive enteral or parenteral nutrition therapies can actually increase the suffering of dying patients. ${ }^{78-81}$ In addition, a recent randomized controlled trial of patients with cancer enrolled in hospice found that parenteral hydration had no effect on dehydration symptoms such as fatigue and hallucination and had no effect on quality of life or survival.82 Therefore, instead of artificial hydration and nutrition, palliative care in the final weeks of life focuses on treating dry mouth and thirst, and providing education and support to the patient and family regarding the emotional aspects of withdrawal of nutritional support. Family members should be informed of alternate ways to care for dying patients.

Nausea and Vomiting: Chemotherapy-induced nausea and vomiting has a major impact on a patient's quality of life. ${ }^{83}$ Nausea and vomiting induced by chemotherapy or radiation therapy should be managed as outlined in the NCCN Guidelines for Antiemesis. Patients can also experience nausea and vomiting unrelated to chemotherapy and radiation, resulting from gastric outlet obstruction, bowel obstruction, constipation, opioid use, or hypercalcemia. ${ }^{84}$ These causes should be identified and treated. Proton pump inhibitors and histamine-2 (H2) receptor antagonists can be used to manage gastritis or gastroesophageal reflux. Gastric outlet obstruction may benefit from treatment with corticosteroids; alternative treatment options include endoscopic stenting or insertion of a decompressing G-tube. Many medications can also cause nausea and vomiting, and blood levels of possible culprits, such as digoxin, phenytoin, car- bamazepine, and tricyclic antidepressants, should be checked. ${ }^{85,86}$

Nonspecific nausea and vomiting can be managed with dopamine receptor antagonists (eg, prochlorperazine, haloperidol, metoclopramide, olanzapine) or benzodiazepines (anxiety-related nausea). Persistent nausea and vomiting can be treated by titrating dopamine receptor antagonists to maximum benefit and tolerance. ${ }^{87-91}$ For persistent nausea, adding 5-HT3 (5-hydroxytryptamine 3) receptor antagonists $^{92,93}$ and/or anticholinergic agents and/or antihistamines, ${ }^{94}$ corticosteroids,,${ }^{94,95}$ continuous or subcutaneous infusion of antiemetics, antipsychotics (eg, olanzapine or haloperidol), ${ }^{96}$ and/or cannabinoids can also be considered. ${ }^{97}$ Opioid rotation may also help alleviate symptoms. ${ }^{98}$ Agents that target the cannabinoid system may offer some efficacy in treating refractory chemotherapy-induced nausea and vomiting. ${ }^{99}$ Dronabinol and nabilone are 2 cannabinoid agents approved for treating chemotherapy-induced nausea and vomiting that are refractory to standard antiemetic therapies. Alternative therapies (eg, acupuncture, hypnosis, cognitive behavioral therapy) can also be considered. ${ }^{100-102}$ Palliative sedation (see subsequent section) can be considered as a last resort if intensified efforts by specialized palliative care or hospice services fail.

A systematic review assessed the level of evidence for antiemesis unrelated to chemotherapy. ${ }^{103}$ Although the authors concluded that antiemetic recommendations have moderate to weak evidence at best, the strongest evidence supports the use of metoclopramide; studies of multidrug combination therapies do not support their effectiveness.

Constipation: Constipation occurs in approximately $50 \%$ of patients with advanced cancer and most patients treated with opioids. ${ }^{104}$ Although several drugs, including antacids, anticholinergic drugs (antidepressants, antispasmodics, phenothiazines, and haloperidol), and antiemetics are known to cause constipation, ${ }^{105}$ opioid analgesics are most commonly associated with constipation. Providers should discontinue any nonessential constipating medications. In addition to physical discomfort, constipation in patients with advanced cancer can cause psychological distress and anxiety regarding continued opioid use. ${ }^{106}$ Opioid-induced constipation should be anticipated and treated prophylactically with a stimulating laxative to increase bowel motility with or without 
stool softeners. ${ }^{107}$ Although little evidence exists on which is the best initial bowel regimen in patients with cancer, ${ }^{108}$ one small study compared the use of senna alone versus a senna-docusate combination. The results demonstrated that the addition of the stool softener docusate was not necessary. ${ }^{109}$ Increasing intake of fluid and physical activity should also be encouraged, when appropriate. Added dietary fiber may be considered for patients with adequate fluid intake.

If constipation is present, the cause and severity must be assessed. Impaction, obstruction, and other treatable causes, such as hypercalcemia, hypokalemia, hypothyroidism, and diabetes mellitus, should be assessed and treated. Constipation may also be treated by adding bisacodyl 10 to $15 \mathrm{mg}, 2$ to 3 times daily with a goal of 1 nonforced bowel movement every 1 to 2 days. If impaction is observed, glycerine suppositories may be administered or manual disimpaction may be performed. If constipation persists, adding other laxatives may be considered, such as rectal bisacodyl once daily or oral polyethylene glycol, lactulose, magnesium hydroxide, or magnesium citrate. ${ }^{108}$ If gastroparesis is suspected, the addition of a prokinetic agent, such as metoclopramide, may be considered.

Peripherally acting $\mu$-opioid receptor antagonists may help to relieve opioid-induced constipation (OIC) while maintaining pain management. Recent studies have shown that methylnaltrexone provided effective relief of OIC while preserving opioid-mediated analgesia. ${ }^{10,111} \mathrm{Naloxegol}$, a similar peripherally-acting $\mu$-opioid receptor antagonist, has also been studied for treating OIC in patients receiving chronic opioids for noncancer pain. ${ }^{112,113}$ Gastrointestinal specialists have reported some success using erythromycin for constipation symptoms that do not respond to peripherally acting $\mu$-opioid receptor antagonists such as methylnaltrexone.

Several newer agents have also been examined for treating constipation. Lubiprostone is an orally active prostaglandin analog that activates select chloride channels to enhance intestinal fluid secretion. ${ }^{14,115}$ This agent was shown to be effective for treating $\mathrm{OIC}$ in patients with chronic noncancer pain. Lubiprostone could be used in combination with a peripherally acting $\mu$-opioid receptor antagonist such as methylnaltrexone. Linaclotide is a selective agonist of guanylate cyclase- $C$ receptors in the intestines to enhance intestinal secretions and has been effective in the treatment of constipation associated with irritable bowel syndrome and chronic idiopathic constipation. ${ }^{116,117}$ The American Gastroenterological Association includes lubiprostone and linaclotide as recommended options for treating constipation associated with irritable bowel disorder. ${ }^{118}$

Based on these results, the NCCN Palliative Care Panel recommends considering $0.15 \mathrm{mg}$ per kilogram of body weight of methylnaltrexone every other day (no more than once/day) for patients experiencing constipation that has not responded to standard laxative therapy. Methylnaltrexone should not be used in patients with a postoperative ileus or mechanical bowel obstruction.

Diarrhea: In patients with cancer, diarrhea can be caused by a number of potential factors, including anticancer treatment-related side effects, infection, antibiotic use, dietary changes, or fecal impaction. ${ }^{119}$ Diarrhea is a common side effect of various chemotherapeutics (eg, fluorouracil and irinotecan), ${ }^{120,121}$ as well tyrosine kinase inhibitors and certain biologic agents (eg, ipilimumab, cetuximab, panitumumab). ${ }^{122}$ Abdominal and pelvic radiation therapy (alone or as part of chemoradiation regimens) can also induce gastrointestinal toxicity resulting in diarrhea. ${ }^{120}$

The National Cancer Institute Common Toxicity Criteria are typically used for measuring diarrhea in this patient population. ${ }^{119}$ The panel recommends that patients be screened to determine the grade of diarrhea. Providers should provide immediate intervention for dehydration based on grade and assess for potential cause(s).

For patients with years, years to months, or months to weeks of estimated life expectancy who have grade 1 or 2 diarrhea, recommendations include hydration and electrolyte replacement (oral or intravenous fluids as appropriate), antidiarrheal medications, and a bland/BRAT (bread, rice, applesauce, toast) diet. For treating grade 2 diarrhea, anticholinergic agents such as hyoscyamine or atropine can be considered. Infection-induced diarrhea should be treated with the appropriate antibiotic. If diarrhea persists, the use of low doses of morphine concentrate can be considered and would be more cost effective than tincture of opium. Patients with persistent grade 2 or grades 3 or 4 diarrhea should receive inpatient treatment. In addition to fluid re- 
placement, antidiarrheal therapy, and anticholinergics, octreotide can also be considered.

For patients with weeks to days of estimated life expectancy, the previously discussed interventions can be considered consistent with the goals of care. At-home intravenous hydration may be considered in addition to scopolamine or hyoscyamine. If diarrhea persists, consider octreotide or glycopyrrolate. Patients should begin around-the-clock opioids or receive an increased dose of ongoing opioid regimens.

Malignant Bowel Obstruction: Malignant bowel obstructions are usually diagnosed clinically and confirmed with radiography. For patients with years to months to live, surgery after CT scan is the primary treatment option. Altthough surgery can lead to improvements in quality of life, surgical risks should be discussed with patients and families. Although surgery is the primary treatment for malignant obstruction, some patients with advanced disease or patients in generally poor condition are not fit for surgery and require alternative management to relieve distressing symptoms. Risk factors for poor surgical outcome include ascites, carcinomatosis, palpable intra-abdominal masses, multiple bowel obstructions, previous abdominal radiation, advanced disease, and poor overall clinical status. ${ }^{123}$ In these patients, medical management can include pharmacologic measures, parenteral fluids, endoscopic management, and enteral tube drainage (silicone tubing may offer superior comfort over vinyl).

Pharmacologic management of malignant bowel obstruction can be seen as different for 2 groups of patients: those for whom the goal is to maintain gut function and those for whom gut function is no longer possible. When the goal is maintaining gut function, patients can be treated with opioids, antiemetics, and corticosteroids, alone or in combination. When gut function is no longer considered possible, pharmacologic options also include somatostatin analogs (eg, octreotide) and/or anticholinergics. ${ }^{124-129}$ If octreotide is helpful and the patient has a life expectancy of at least 1 month, it may be beneficial to consider a depot form of octreotide once an optimal dose is established. Antiemetics that increase gastrointestinal mobility such as metoclopramide should not be used in patients with complete obstruction, but may be beneficial when obstruction is partial. Use of octreotide is recommended early in the diagnosis be- cause of its efficacy and tolerability. ${ }^{130,131}$ Despite positive findings from several smaller randomized trials, a recent phase III trial of octreotide in 86 patients with malignant bowel obstruction failed to demonstrate a significant effect of this drug on days free of vomiting, number of vomiting episodes, symptom management, and other secondary endpoints. ${ }^{132}$

A venting gastrostomy tube (inserted by interventional radiology, endoscopy, or surgery departments), a percutaneous endoscopic gastrostomy tube, or an endoscopically placed stent can also palliate symptoms of malignant bowel obstruction. ${ }^{133,134}$ Total parenteral nutrition can be considered to improve quality of life in patients with a life expectancy of years to months. These interventions have been shown to have little positive impact on survival time, but may improve quality of life. ${ }^{7,8}$

Fatigue/Weakness/Asthenia: The data on methylphenidate for treating cancer-related fatigue have been mixed. ${ }^{135}$ Although some trials have suggested a dose-dependent benefit of this agent on fatigue symptoms, ${ }^{136,137}$ other studies have failed to produce positive results. ${ }^{138}$ Phase III randomized trials of modafinil for treating cancer-related fatigue suggested that modafinil had a modest efficacy and was most effective for those with severe fatigue. ${ }^{139,140}$ For more information, see the NCCN Guidelines for CancerRelated Fatigue (available at NCCN.org).

Sleep/Wake Disturbances: Patients with cancer often suffer from insomnia or daytime sedation. ${ }^{141-143}$ In a recent study of 442 patients with advanced cancer, $330(75 \%)$ patients were noted to have baseline sleep disturbance as assessed using the Edmonton Symptom Assessment System (ESAS) sleep item. ${ }^{144}$ Patients should first be evaluated for sleep/wake disturbances using, for example, the Epworth Sleepiness Scale. ${ }^{145}$ If patients have a history of sleep-disordered breathing (eg, excessive snoring, gasping for air, observed apneas, frequent arousals, sudden involuntary movement of arm or legs during sleep, unexplained daytime drowsiness), polysomnography should be considered. Polysomnography should also be considered for patients with head and neck cancers, because obstructive sleep apnea (OSA) is prevalent in patients with this disease. ${ }^{146,147}$ Primary sleep disorders, such as OSA and periodic limb movement disorder, should be treated with continuous positive airway pressure (CPAP) or BiPAP. ${ }^{148}$ Restless leg syndrome, if present, can be treated with ropinirole, pramipex- 
ole with pregabalin, or carbidopa-levodopa. ${ }^{149-157}$ Fears and anxiety regarding death and disease should be explored, and other contributing factors to sleep/ wake disturbances should be treated, including pain, depression, anxiety, delirium, and nausea. Cognitive behavioral therapy may be effective in treating sleep/ wake disturbances in patients with cancer. ${ }^{33,158-162}$

For refractory insomnia, pharmacologic management includes the short-acting benzodiazepine lorazepam, the nonbenzodiazepine zolpidem, antipsychotic medications such as chlorpromazine, quetiapine, and olanzapine, and sedating antidepressants such as trazodone and mirtazapine. ${ }^{163}$ The panel suggests that mirtazapine may be especially effective in patients with depression and anorexia. Benzodiazepines should be avoided in older patients and in patients with cognitive impairment, because they have been shown to cause decreased cognitive performance. ${ }^{164}$ Caution should be exercised when administering zolpidem due to the known risk of next-morning impairment. In 2013, the US FDA required lower recommended doses of zolpidem (ie, from 10 to $5 \mathrm{mg}$ for immediate-release products and from 12.5 to $6.25 \mathrm{mg}$ for extended-release formulations). ${ }^{165}$

For refractory daytime sedation, the guidelines suggest several options. The central nervous system stimulants methylphenidate or dextroamphetamine should be given with a starting dose of 2.5 to $5 \mathrm{mg}$ orally with breakfast. If the effect of the drug does not last through lunch, a second dose can be given at lunch, preferably no later than 2:00 PM. Doses can be escalated as needed. ${ }^{166}$ Another option for refractory daytime sedation is the psychostimulant modafinil, which has been approved in adults for excessive sleepiness associated with OSA/hypopnea syndrome (OSAHS), shift work sleep disorder, and narcolepsy. ${ }^{167}$ The panel also recommends caffeine and dextroamphetamine as additional options for refractory daytime sedation. The last dose of caffeine should be given no later than 4:00 PM.

Dying patients should be assessed for their desire to have their insomnia or sedation treated. The doses of their pharmacologic therapies can be adjusted as appropriate. The addition of an antipsychotic drug (chlorpromazine or quetiapine) can be considered in patients whose insomnia is refractory.

Please also see the NCCN Guidelines for Adult Cancer Pain and the NCCN Guidelines for Cancer-
Related Fatigue for their discussions on sleep/wake disturbances (available at NCCN.org).

Delirium: Delirium should be assessed using the Diagnostic and Statistical Manual of Mental Disorders, Fourth Edition (DSM-IV) criteria. $^{168}$ Reversible causes should be identified and treated appropriately. ${ }^{169}$ Delirium may present as either a hypoactive or a hyperactive subtype. ${ }^{170}$ Recent studies have suggested that hypoactive delirium was the most prevalent subtype in patients under palliative care and that this condition is often underdiagnosed due to its presentation. ${ }^{171,172}$

Two comprehensive reviews describe the evidence base for recommended pharmacologic and nonpharmacologic treatments for delirium in patients with cancer. ${ }^{33,173}$ Nonpharmacologic interventions (eg, reorientation, cognitive stimulation, sleep hygiene) should be maximized before pharmacologic interventions are used. Delirium-inducing medications (ie, steroids, anticholinergics) should be reduced or eliminated as much as possible. ${ }^{174}$ Benzodiazepines should not be used as initial treatment for delirium in patients not already taking them.

The symptoms of moderate delirium can be managed with oral haloperidol, risperidone, olanzapine, or quetiapine fumarate. ${ }^{175-177}$ The symptoms of severe delirium (ie, agitation) should be managed with antipsychotic, neuroleptic drugs such as haloperidol, olanzapine, or chlorpromazine. ${ }^{178}$ Because of its hypotensive side effect, intravenous chlorpromazine should only be used in bed-bound patients. A benzodiazepine, such as lorazepam, may be added for agitation that is refractory to high doses of neuroleptics. ${ }^{179}$ The presence of therapeutic levels of neuroleptics usually prevents the paradoxic excitation sometimes seen when delirious patients are given lorazepam. The dosages of these symptom-management medications should be titrated to optimal relief. Opioid dose reduction or rotation can also be considered for patients with severe delirium. Caregivers should be supported in caring for their loved one and coping with this distressing condition.

Delirium in patients with advanced cancer and limited life expectancy may shorten prognosis. ${ }^{180}$ In these patients, iatrogenic causes should be eliminated whenever possible. Opioid rotation can be considered (see NCCN Guidelines for Adult Cancer Pain) if the delirium is believed to be caused by neurotoxicity of the current opioid. If delirium is a 
result of disease progression, palliative care must be focused on symptom management and family support. Neuroleptic and benzodiazepine medications should have their dose increased and/or their route of administration changed to ensure adequate delirium symptom management. ${ }^{181}$ Unnecessary medications and tubes should be removed. For refractory delirium in dying patients, palliative sedation can be considered after consultation with a palliative care specialist and/or psychiatrist. Please also see the NCCN Guidelines for Distress Management (available at NCCN.org) for further discussion of delirium in patients with cancer.

\section{Conclusions}

These guidelines are intended to help oncology teams provide the best care possible for patients with incurable cancer. Patients with advanced disease frequently are overly optimistic about their chances of cure, treatment response, symptom relief, and survival. One study found that those who overestimated their survival were more likely to die a bad death. ${ }^{182}$ Using a decision aid, Smith et $\mathrm{al}^{183}$ found that most patients want honest information, even if it is bad news. Although use of the decision aid typically took 20 minutes and was challenging for oncologists, it did not cause patients to give up hope or become distressed. Physician-led discussion of disease progression and death can improve quality of care and quality of life for both patients and families. ${ }^{184}$ Providing information in a collaborative manner protects the autonomy of patients to make informed decisions based on potential treatment outcomes. ${ }^{185}$ Palliative care can help patients and families set realistic expectations and meet short- and longer-term goals, such as important life-cycle events. Much of the care outlined in these guidelines is geared toward a different hope than that for cure of the disease itself. ${ }^{183,186,187}$ Even when cure is no longer possible, hope remains: hope for dignity, comfort, and closure and for growth at the end of life. It is our hope that these guidelines will help oncology and palliative care professionals together create a better future for patients, families, and providers.

\section{References}

1. Berger A, Portenoy R, Weissman D, eds. Practice and Principles of Supportive Oncology. Philadelphia: Lippincott-Raven; 1998.
2. Doyle D, Hanks G, MacDonald Ne, eds. Oxford Textbook of Palliative Medicine. Oxford: Oxford University; 1998.

3. Emanuel L, von Gunten C, FD F, eds. The Education for Physicians on End-of-Life Care (EPEC) Curriculum. Princeton: The Robert Wood Johnson Foundation; 1999.

4. Cleeland CS, Zhao F, Chang VT, et al. The symptom burden of cancer: evidence for a core set of cancer-related and treatment-related symptoms from the Eastern Cooperative Oncology Group Symptom Outcomes and Practice Patterns study. Cancer 2013;119:4333-4340.

5. Smith TJ, Temin S, Alesi ER, et al. American Society of Clinical Oncology Provisional Clinical Opinion: the integration of palliative care into standard oncology care. J Clin Oncol 2012;30:880-887.

6. Temel JS, Greer JA, Muzikansky A, et al. Early palliative care for patients with metastatic non-small-cell lung cancer. N Engl J Med 2010;363:733742 .

7. Diver E, O'Connor O, Garrett L, et al. Modest benefit of total parenteral nutrition and chemotherapy after venting gastrostomy tube placement. Gynecol Oncol 2013;129:332-335.

8. Richards DM, Tanikella R, Arora G, et al. Percutaneous endoscopic gastrostomy in cancer patients: predictors of 30-day complications, 30-day mortality, and overall mortality. Dig Dis Sci 2013;58:768-776.

9. Salpeter SR, Malter DS, Luo EJ, et al. Systematic review of cancer presentations with a median survival of six months or less. J Palliat Med 2012;15:175-185.

10. Communicating with Patients on Health Care Evidence. Institute of Medicine; 2012. Available at: http://www.iom.edu/Global/ Perspectives/2012/Evidence.aspx. Accessed May 17, 2013.

11. Novelli WD, Halvorson GC, Santa J. Recognizing an Opinion: Findings From the IOM Evidence Communication Innovation Collaborative JAMA 2012;308:1531-1532.

12. Freelove R, Walling AD. Pancreatic cancer: diagnosis and management. Am Fam Physician 2006;73:485-492.

13. Guarneri V, Conte PF. The curability of breast cancer and the treatment of advanced disease. Eur J Nucl Med Mol Imaging 2004;31 Suppl 1:S149-161.

14. Pienta KJ, Smith DC. Advances in prostate cancer chemotherapy: a new era begins. CA Cancer J Clin 2005;55:300-318; quiz 323-305.

15. Prommer E. Guidelines for the Use of Palliative Chemotherapy. AAHPM Bulletin 2004;5:2-13.

16. Ajani JA. Evolving chemotherapy for advanced gastric cancer. Oncologist 2005;10 Suppl 3:49-58.

17. Brown J, Thorpe H, Napp V, et al. Assessment of quality of life in the supportive care setting of the big lung trial in non-small-cell lung cancer. J Clin Oncol 2005;23:7417-7427.

18. Silvestri GA, Rivera MP. Targeted therapy for the treatment of advanced non-small cell lung cancer: a review of the epidermal growth factor receptor antagonists. Chest 2005;128:3975-3984.

19. Chen AB, Cronin A, Weeks JC, et al. Palliative radiation therapy practice in patients with metastatic non-small-cell lung cancer: a Cancer Care Outcomes Research and Surveillance Consortium (CanCORS) Study. J Clin Oncol 2013;31:558-564.

20. Zafar SY, Malin JL, Grambow SC, et al. Chemotherapy use and patient treatment preferences in advanced colorectal cancer: a prospective cohort study. Cancer 2013;119:854-862.

21. Higginson IJ, Finlay IG, Goodwin DM, et al. Is there evidence that palliative care teams alter end-of-life experiences of patients and their caregivers? J Pain Symptom Manage 2003;25:150-168.

22. Kinzbrunner BM. Hospice: what to do when anti-cancer therapy is no longer appropriate, effective, or desired. Semin Oncol 1994;21:792-798.

23. Trajkovic-Vidakovic M, de Graeff A, Voest EE, Teunissen SC. Symptoms tell it all: a systematic review of the value of symptom assessment to predict survival in advanced cancer patients. Crit Rev Oncol Hematol 2012;84:130-148.

24. Yennurajalingam S, Kwon JH, Urbauer DL, et al. Consistency of symptom clusters among advanced cancer patients seen at an outpatient supportive care clinic in a tertiary cancer center. Palliat Support Care 2013;11:473480.

25. Van Lancker A, Velghe A, Van Hecke A, et al. Prevalence of symptoms in older cancer patients receiving palliative care: a systematic review and meta-analysis. J Pain Symptom Manage 2014;47:90-104.

26. Ferrell B, Levy MH, Paice J. Managing pain from advanced cancer in the palliative care setting. Clin J Oncol Nurs 2008;12:575-581. 
27. Temel JS, Pirl WF, Lynch TJ. Comprehensive symptom management in patients with advanced-stage non-small-cell lung cancer. Clin Lung Cancer 2006; 7:241-249.

28. Dyspnea. Mechanisms, assessment, and management: a consensus statement. American Thoracic Society. Am J Respir Crit Care Med 1999; 159:321-340.

29. DeCamp MM, Jr., Mentzer SJ, Swanson SJ, Sugarbaker DJ. Malignant effusive disease of the pleura and pericardium. Chest 1997;112:291S-295S.

30. Dy SM, Lorenz KA, Naeim A, et al. Evidence-based recommendations for cancer fatigue, anorexia, depression, and dyspnea. J Clin Oncol 2008;26:3886-3895

31. Swanson N, Mirza I, Wijesinghe N, Devlin G. Primary percutaneous balloon pericardiotomy for malignant pericardial effusion. Catheter Cardiovasc Interv 2008; 71:504-507.

32. Xue D, Abernethy AP. Management of dyspnea in advanced lung cancer: recent data and emerging concepts. Curr Opin Support Palliat Care 2010;4:85-91

33. Dy SM, Apostol CC. Evidence-based approaches to other symptoms in advanced cancer. Cancer J 2010;16:507-513.

34. Ben-Aharon I, Gafter-Gvili A, Paul M, et al. Interventions for alleviating cancer-related dyspnea: a systematic review. J Clin Oncol 2008;26:23962404.

35. Ben-Aharon I, Gafter-Gvili A, Leibovici L, Stemmer SM. Interventions for alleviating cancer-related dyspnea: a systematic review and meta analysis. Acta Oncol 2012;51:996-1008.

36. Clemens KE, Quednau I, Klaschik E. Is there a higher risk of respiratory depression in opioid-naive palliative care patients during symptomatic therapy of dyspnea with strong opioids? J Palliat Med 2008;11:204-216.

37. Gomutbutra P, O'Riordan DL, Pantilat SZ. Management of Moderate-toSevere Dyspnea in Hospitalized Patients Receiving Palliative Care. J Pain Symptom Manage 2012

38. Jennings AL, Davies AN, Higgins JP, et al. A systematic review of the use of opioids in the management of dyspnoea. Thorax 2002;57:939-944.

39. Simon ST, Higginson IJ, Booth S, et al. Benzodiazepines for the relief of breathlessness in advanced malignant and non-malignant diseases in adults. Cochrane Database Syst Rev 2010:CD007354.

40. Coyne PJ, Viswanathan R, Smith TJ. Nebulized fentanyl citrate improves patients' perception of breathing, respiratory rate, and oxygen saturation in dyspnea. J Pain Symptom Manage 2002;23:157-160.

41. Smith TJ, Coyne P, French W, et al. Failure to accrue to a study of nebulized fentanyl for dyspnea: lessons learned. J Palliat Med 2009;12:771-772.

42. Simon ST, Koskeroglu P, Gaertner J, Voltz R. Fentanyl for the relief of refractory breathlessness: a systematic review. J Pain Symptom Manage 2013;46:874-886.

43. Hui D, Xu A, Frisbee-Hume $S$, et al. Effects of prophylactic subcutaneous fentanyl on exercise-induced breakthrough dyspnea in cancer patients: a preliminary double-blind, randomized, controlled trial. J Pain Symptom Manage 2014:47:209-217.

44. Jensen D, Alsuhail A, Viola R, et al. Inhaled Fentanyl Citrate Improves Exercise Endurance During High-Intensity Constant Work Rate Cycle Exercise in Chronic Obstructive Pulmonary Disease. J Pain Symptom Manage 2011

45. Kawabata M, Kaneishi K. Continuous subcutaneous infusion of compound oxycodone for the relief of dyspnea in patients with terminally ill cancer: a retrospective study. Am J Hosp Palliat Care 2013;30:305-311.

46. Back IN, Jenkins K, Blower A, Beckhelling J. A study comparing hyoscine hydrobromide and glycopyrrolate in the treatment of death rattle. Palliat Med 2001;15:329-336.

47. Davis MP, Furste A. Glycopyrrolate: a useful drug in the palliation of mechanical bowel obstruction. J Pain Symptom Manage 1999;18:153-154.

48. Hughes A, Wilcock A, Corcoran R, et al. Audit of three antimuscarinic drugs for managing retained secretions. Palliat Med 2000;14:221-222.

49. Wildiers $H$, Menten J. Death rattle: prevalence, prevention and treatment. J Pain Symptom Manage 2002;23:310-317.

50. Wildiers H, Dhaenekint C, Demeulenaere P, et al. Atropine, hyoscine butylbromide, or scopolamine are equally effective for the treatment of death rattle in terminal care. J Pain Symptom Manage 2009;38:124-133.

51. Grum DF, Osborne LR. Central anticholinergic syndrome following glycopyrrolate. Anesthesiology 1991;74:191-193.

52. Wingard DW. Glycopyrrolate and the central anticholinergic syndrome. Anesthesiology 1991;75:1125-1126.

53. Mirakhur RK, Dundee JW. Glycopyrrolate: pharmacology and clinical use. Anaesthesia 1983;38:1195-1204.
54. Death Rattle and Oral Secretions, 2nd ed. End of Life / Palliative Education Resource Center (EPERC); Available at: http://www.eperc. mcw.edu/EPERC/FastFactsIndex/ff_109.htm. Accessed May 20, 2013.

55. Galbraith S, Fagan P, Perkins P, et al. Does the use of a handheld fan improve chronic dyspnea? A randomized, controlled, crossover trial. J Pain Symptom Manage 2010;39:831-838.

56. Abernethy AP, McDonald CF, Frith PA, et al. Effect of palliative oxygen versus room air in relief of breathlessness in patients with refractory dyspnoea: a double-blind, randomised controlled trial. Lancet 2010;376:784-793

57. Nava S, Ferrer M, Esquinas A, et al. Palliative use of non-invasive ventilation in end-of-life patients with solid tumours: a randomised feasibility trial. Lancet Oncol 2013;14:219-227.

58. Hui D, Morgado M, Chisholm G, et al. High-flow oxygen and bilevel positive airway pressure for persistent dyspnea in patients with advanced cancer: a phase II randomized trial. J Pain Symptom Manage 2013;46:463473.

59. Kumar NB, Kazi A, Smith T, et al. Cancer cachexia: traditional therapies and novel molecular mechanism-based approaches to treatment. Curr Treat Options Oncol 2010;11:107-117.

60. Laviano A, Meguid MM, Inui A, et al. Therapy insight: Cancer anorexiacachexia syndrome: when all you can eat is yourself. Nat Clin Pract Oncol 2005;2:158-165.

61. Oberholzer R, Hopkinson JB, Baumann K, et al. Psychosocial Effects of Cancer Cachexia: A Systematic Literature Search and Qualitative Analysis. J Pain Symptom Manage 2012.

62. Martin L, Birdsell L, Macdonald N, et al. Cancer cachexia in the age of obesity: skeletal muscle depletion is a powerful prognostic factor, independent of body mass index. J Clin Oncol 2013;31:1539-1547.

63. Pascual Lopez A, Roque i Figuls M, Urrutia Cuchi G, et al. Systematic review of megestrol acetate in the treatment of anorexia-cachexia syndrome. J Pain Symptom Manage 2004;27:360-369.

64. Ruiz Garcia V, Lopez-Briz E, Carbonell Sanchis R, et al. Megestrol acetate for treatment of anorexia-cachexia syndrome. Cochrane Database Syst Rev 2013;3:CD004310.

65. Yavuzsen T, Davis MP, Walsh D, et al. Systematic review of the treatment of cancer-associated anorexia and weight loss. J Clin Oncol 2005;23:85008511.

66. Miller S, McNutt L, McCann MA, McCorry N. Use of corticosteroids for anorexia in palliative medicine: a systematic review. J Palliat Med 2014;17:482-485.

67. Navari RM, Brenner MC. Treatment of cancer-related anorexia with olanzapine and megestrol acetate: a randomized trial. Support Care Cancer 2010;18:951-956.

68. Mantovani G, Maccio A, Madeddu C, et al. Randomized phase III clinical trial of five different arms of treatment in 332 patients with cancer cachexia. Oncologist 2010;15:200-211.

69. Maccio A, Madeddu C, Gramignano G, et al. A randomized phase III clinical trial of a combined treatment for cachexia in patients with gynecological cancers: evaluating the impact on metabolic and inflammatory profiles and quality of life. Gynecol Oncol 2012;124:417-425

70. Walsh D, Nelson KA, Mahmoud FA. Established and potential therapeutic applications of cannabinoids in oncology. Support Care Cancer 2003;11:137-143.

71. Strasser F, Luftner D, Possinger K, et al. Comparison of orally administered cannabis extract and delta-9-tetrahydrocannabinol in treating patients with cancer-related anorexia-cachexia syndrome: a multicenter, phase III, randomized, double-blind, placebo-controlled clinical trial from the Cannabis-In-Cachexia-Study-Group. J Clin Oncol 2006;24:3394-3400.

72. Jatoi A, Windschitl HE, Loprinzi CL, et al. Dronabinol versus megestrol acetate versus combination therapy for cancer-associated anorexia: a North Central Cancer Treatment Group study. J Clin Oncol 2002;20:567-573.

73. Isenring EA, Capra S, Bauer JD. Nutrition intervention is beneficial in oncology outpatients receiving radiotherapy to the gastrointestinal or head and neck area. Br J Cancer 2004;91:447-452.

74. Ravasco P, Monteiro-Grillo I, Vidal PM, Camilo ME. Dietary counseling improves patient outcomes: a prospective, randomized, controlled trial in colorectal cancer patients undergoing radiotherapy. J Clin Oncol 2005;23:1431-1438.

75. Trentham K. Palliative Care. In: Marian M, Roberts S, eds. Clinical Nutrition for Oncology Patients. Sudbury, MA: Jones and Bartlett Publishers LLC; 2010.

76. Baldwin C, Spiro A, McGough C, et al. Simple nutritional intervention in patients with advanced cancers of the gastrointestinal tract, non-small cell 
lung cancers or mesothelioma and weight loss receiving chemotherapy: a randomised controlled trial. J Hum Nutr Diet 2011;24:431-440.

77. Baldwin C, Spiro A, Ahern R, Emery PW. Oral nutritional interventions in malnourished patients with cancer: a systematic review and metaanalysis. J Natl Cancer Inst 2012;104:371-385.

78. August DA, Huhmann MB. A.S.P.E.N. clinical guidelines: nutrition support therapy during adult anticancer treatment and in hematopoietic cell transplantation. JPEN J Parenter Enteral Nutr 2009;33:472-500.

79. McCann RM, Hall WJ, Groth-Juncker A. Comfort care for terminally ill patients. The appropriate use of nutrition and hydration. JAMA 1994;272:1263-1266.

80. Weiner RS, Kramer BS, Clamon GH, et al. Effects of intravenous hyperalimentation during treatment in patients with small-cell lung cancer. J Clin Oncol 1985;3:949-957.

81. Winter SM. Terminal nutrition: framing the debate for the withdrawal of nutritional support in terminally ill patients. Am J Med 2000;109:723-726.

82. Bruera E, Hui D, Dalal S, et al. Parenteral hydration in patients with advanced cancer: a multicenter, double-blind, placebo-controlled randomized trial. J Clin Oncol 2013;31:111-118.

83. Schwartzberg L. Chemotherapy-induced nausea and vomiting: state of the art in 2006. J Support Oncol 2006;4:3-8.

84. Shoemaker LK, Estfan B, Induru R, Walsh TD. Symptom management: an important part of cancer care. Cleve Clin J Med 2011;78:25-34.

85. Holt DW, Volans GN. Gastrointestinal symptoms of digoxin toxicity. $\mathrm{Br}$ Med J 1977;2:704

86. Hwang WJ, Tsai JJ. Acute phenytoin intoxication: causes, symptoms, misdiagnoses, and outcomes. Kaohsiung J Med Sci 2004;20:580-585.

87. Hardy JR, O'Shea A, White C, et al. The efficacy of haloperidol in the management of nausea and vomiting in patients with cancer. J Pain Symptom Manage 2010;40:111-116.

88. Gralla RJ, Itri LM, Pisko SE, et al. Antiemetic efficacy of high-dose metoclopramide: randomized trials with placebo and prochlorperazine in patients with chemotherapy-induced nausea and vomiting. N Engl J Med 1981;305:905-909.

89. Buzdar AU, Esparza L, Natale R, et al. Lorazepam-enhancement of the antiemetic efficacy of dexamethasone and promethazine. A placebocontrolled study. Am J Clin Oncol 1994;17:417-421.

90. Tan L, Liu J, Liu X, et al. Clinical research of Olanzapine for prevention of chemotherapy-induced nausea and vomiting. J Exp Clin Cancer Res 2009;28:131.

91. Navari RM, Gray SE, Kerr AC. Olanzapine versus aprepitant for the prevention of chemotherapy-induced nausea and vomiting: a randomized phase III trial. J Support Oncol 2011;9:188-195.

92. Grunberg SM, Stevenson LL, Russell CA, McDermed JE. Dose ranging phase I study of the serotonin antagonist GR38032F for prevention of cisplatin-induced nausea and vomiting. J Clin Oncol 1989;7:1137-1141.

93. Marty M, Pouillart $\mathrm{P}$, Scholl S, et al. Comparison of the 5-hydroxytryptamine3 (serotonin) antagonist ondansetron (GR 38032F) with high-dose metoclopramide in the control of cisplatin-induced emesis. N Engl J Med 1990;322:816-821.

94. Kris MG, Gralla RJ, Clark RA, et al. Antiemetic control and prevention of side effects of anti-cancer therapy with lorazepam or diphenhydramine when used in combination with metoclopramide plus dexamethasone. A double-blind, randomized trial. Cancer 1987;60:2816-2822.

95. Aapro MS, Plezia PM, Alberts DS, et al. Double-blind crossover study of the antiemetic efficacy of high-dose dexamethasone versus high-dose metoclopramide. J Clin Oncol 1984;2:466-471.

96. Navari RM, Einhorn LH, Passik SD, et al. A phase II trial of olanzapine for the prevention of chemotherapy-induced nausea and vomiting: a Hoosier Oncology Group study. Support Care Cancer 2005;13:529-534.

97. Herman TS, Einhorn LH, Jones SE, et al. Superiority of nabilone over prochlorperazine as an antiemetic in patients receiving cancer chemotherapy. N Engl J Med 1979;300:1295-1297.

98. Morita $\mathrm{T}$, Takigawa $\mathrm{C}$, Onishi $\mathrm{H}$, et al. Opioid rotation from morphine to fentanyl in delirious cancer patients: an open-label trial. J Pain Symptom Manage 2005;30:96-103.

99. Slatkin NE. Cannabinoids in the treatment of chemotherapy-induced nausea and vomiting: beyond prevention of acute emesis. J Support Oncol 2007;5:1-9.

100. Mamtani R, Cimino A. A primer of complementary and alternative medicine and its relevance in the treatment of mental health problems. Psychiatr Q 2002;73:367-381.
101. Mansky PJ, Wallerstedt DB. Complementary medicine in palliative care and cancer symptom management. Cancer J 2006;12:425-431.

102. Marchioro G, Azzarello G, Viviani F, et al. Hypnosis in the treatment of anticipatory nausea and vomiting in patients receiving cancer chemotherapy. Oncology 2000;59:100-104

103. Davis MP, Hallerberg G. A systematic review of the treatment of nausea and/or vomiting in cancer unrelated to chemotherapy or radiation. J Pain Symptom Manage 2010;39:756-767.

104. Becker G, Galandi D, Blum HE. Peripherally acting opioid antagonists in the treatment of opiate-related constipation: a systematic review. J Pain Symptom Manage 2007;34:547-565.

105. Mancini I, Bruera E. Constipation in advanced cancer patients. Support Care Cancer 1998;6:356-364.

106. Dhingra L, Shuk E, Grossman B, et al. A qualitative study to explore psychological distress and illness burden associated with opioid-induced constipation in cancer patients with advanced disease. Palliat Med 2013;27:447-456.

107. American Pain Socitey. Principles ofAnalgesic use in the treatment of acute pain and cancer pain (ed 5th). Glenview, IL: American Pain Society; 2003.

108. Candy B, Jones L, Larkin PJ, et al. Laxatives for the management of constipation in people receiving palliative care. Cochrane Database Syst Rev 2015;5:CD003448.

109. Hawley PH, Byeon JJ. A comparison of sennosides-based bowel protocols with and without docusate in hospitalized patients with cancer. J Palliat Med 2008;11:575-581.

110. Portenoy RK, Thomas J, Moehl Boatwright ML, et al. Subcutaneous methylnaltrexone for the treatment of opioid-induced constipation in patients with advanced illness: a double-blind, randomized, parallel group, dose-ranging study. J Pain Symptom Manage 2008;35:458-468.

111. Thomas J, Karver S, Cooney GA, et al. Methylnaltrexone for opioidinduced constipation in advanced illness. N Engl J Med 2008;358:23322343.

112. Webster L, Chey WD, Tack J, et al. Randomised clinical trial: the longterm safety and tolerability of naloxegol in patients with pain and opioidinduced constipation. Aliment Pharmacol Ther 2014;40:771-779.

113. Chey WD, Webster L, Sostek M, et al. Naloxegol for opioidinduced constipation in patients with noncancer pain. N Engl J Med 2014;370:2387-2396

114. Jamal MM, Adams AB, Jansen JP, Webster LR. A randomized, placebocontrolled trial of lubiprostone for opioid-induced constipation in chronic noncancer pain. Am J Gastroenterol 2015;110:725-732.

115. Lacy BE, Levy LC. Lubiprostone: a novel treatment for chronic constipation. Clin Interv Aging 2008;3:357-364.

116. Chey WD, Lembo AJ, Lavins BJ, et al. Linaclotide for irritable bowel syndrome with constipation: a 26-week, randomized, double-blind, placebo-controlled trial to evaluate efficacy and safety. Am J Gastroenterol 2012;107:1702-1712.

117. Chang L, Lembo AJ, Lavins BJ, et al. The impact of abdominal pain on global measures in patients with chronic idiopathic constipation, before and after treatment with linaclotide: a pooled analysis of two randomised, double-blind, placebo-controlled, phase 3 trials. Aliment Pharmacol Ther 2014;40:1302-1312.

118. Weinberg DS, Smalley W, Heidelbaugh JJ, et al. American Gastroenterological Association Institute Guideline on the pharmacological management of irritable bowel syndrome. Gastroenterology 2014;147:1146-1148.

119. $P D Q \circledR$ Gastrointestinal Complications. Bethesda, MD: National Cancer Institute; Available at: http://cancer.gov/cancertopics/pdq/supportivecare/ gastrointestinalcomplications/HealthProfessional. Accessed March 17 2015.

120. Benson AB, 3rd, Ajani JA, Catalano RB, et al. Recommended guidelines for the treatment of cancer treatment-induced diarrhea. J Clin Oncol 2004;22:2918-2926.

121. Andreyev J, Ross P, Donnellan C, et al. Guidance on the management of diarrhoea during cancer chemotherapy. Lancet Oncol 2014;15:e447-460.

122. Pessi MA, Zilembo N, Haspinger ER, et al. Targeted therapy-induced diarrhea: A review of the literature. Crit Rev Oncol Hematol 2014;90:165179.

123. Francescutti V, Miller A, Satchidanand $Y$, et al. Management of bowel obstruction in patients with stage IV cancer: predictors of outcome after surgery. Ann Surg Oncol 2013;20:707-714. 
124. Feuer DJ, Broadley KE. Corticosteroids for the resolution of malignant bowel obstruction in advanced gynaecological and gastrointestinal cancer. Cochrane Database Syst Rev 2000:CD001219.

125. Kaneishi $K$, Kawabata M, Morita T. Olanzapine for the relief of nausea in patients with advanced cancer and incomplete bowel obstruction. J Pain Symptom Manage 2012;44:604-607.

126. Porzio G, Aielli F, Verna L, et al. Can malignant bowel obstruction in advanced cancer patients be treated at home? Support Care Cancer 2011;19:431-433.

127. Mercadante S, Ferrera P, Villari P, Marrazzo A. Aggressive pharmacological treatment for reversing malignant bowel obstruction. J Pain Symptom Manage 2004;28:412-416.

128. Zelek L, Laval G, Asselain B. Somatostatin analogs for malignant bowel obstruction resulting from peritoneal carcinomatosis. J Clin Oncol 2013;31:2519-2520.

129. Berger J, Lester P, Rodrigues L. Medical Therapy of Malignant Bowel Obstruction With Octreotide, Dexamethasone, and Metoclopramide. Am J Hosp Palliat Care 2015.

130. Mercadante S, Casuccio A, Mangione S. Medical treatment for inoperable malignant bowel obstruction: a qualitative systematic review. J Pain Symptom Manage 2007;33:217-223.

131. Mercadante S, Porzio G. Octreotide for malignant bowel obstruction: twenty years after. Crit Rev Oncol Hematol 2012;83:388-392.

132. Currow DC, Clark $K$, Cartmill J, et al. A multi-site, fixed dose, parallel arm, double-blind, placebo controlled, block randomised trial of the addition of infusional octreotide or placebo to regular ranitidine and dexamethasone for the evaluation of vomiting associated with bowel obstruction at the end of life. [Abstract]. 2012 ASCO Annual Meeting: American Society for Clinical Oncology; 2012:TPS9153. Available at: http://meetinglibrary. asco.org/content/101301-114.

133. Baron TH. Interventional palliative strategies for malignant bowel obstruction. Curr Oncol Rep 2009;11:293-297.

134. Brooksbank MA, Game PA, Ashby MA. Palliative venting gastrostomy in malignant intestinal obstruction. Palliat Med 2002;16:520-526.

135. Mucke M, Mochamat, Cuhls $\mathrm{H}$, et al. Pharmacological treatments for fatigue associated with palliative care. Cochrane Database Syst Rev 2015;5:CD006788.

136. Escalante CP, Meyers C, Reuben JM, et al. A randomized, doubleblind, 2-period, placebo-controlled crossover trial of a sustained-release methylphenidate in the treatment of fatigue in cancer patients. Cancer J 2014;20:8-14.

137. Gong $\mathrm{S}$, Sheng $\mathrm{P}$, Jin $\mathrm{H}$, et al. Effect of methylphenidate in patients with cancer-related fatigue: a systematic review and meta-analysis. PLoS One 2014;9:e84391.

138. Moraska AR, Sood A, Dakhil SR, et al. Phase III, randomized, doubleblind, placebo-controlled study of long-acting methylphenidate for cancerrelated fatigue: North Central Cancer Treatment Group NCCTG-N05C7 trial. J Clin Oncol 2010;28:3673-3679.

139. Hovey E, de Souza P, Marx G, et al. Phase III, randomized, double-blind, placebo-controlled study of modafinil for fatigue in patients treated with docetaxel-based chemotherapy. Support Care Cancer 2014;22:1233-1242.

140. Jean-Pierre P, Morrow GR, Roscoe JA, et al. A phase 3 randomized placebo-controlled, double-blind, clinical trial of the effect of modafinil on cancer-related fatigue among 631 patients receiving chemotherapy: a University of Rochester Cancer Center Community Clinical Oncology Program Research base study. Cancer 2010;116:3513-3520.

141. Palesh OG, Roscoe JA, Mustian KM, et al. Prevalence, demographics, and psychological associations of sleep disruption in patients with cancer: University of Rochester Cancer Center-Community Clinical Oncology Program. J Clin Oncol 2010;28:292-298.

142. Savard J, Ivers H, Villa J, et al. Natural course of insomnia comorbid with cancer: an 18-month longitudinal study. J Clin Oncol 2011;29:3580-3586.

143. Palesh $O$, Aldridge-Gerry A, Ulusakarya A, et al. Sleep disruption in breast cancer patients and survivors. J Natl Compr Canc Netw 2013;11:15231530.

144. Yennurajalingam S, Chisholm G, Palla SL, et al. Self-reported sleep disturbance in patients with advanced cancer: Frequency, intensity, and factors associated with response to outpatient supportive care consultation: a preliminary report. Palliat Support Care 2013:1-9.

145. Johns MW. A new method for measuring daytime sleepiness: the Epworth sleepiness scale. Sleep 1991;14:540-545.

146. Payne RJ, Hier MP, Kost KM, et al. High prevalence of obstructive sleep apnea among patients with head and neck cancer. J Otolaryngol 2005;34:304-311.
147. Stern TP, Auckley D. Obstructive sleep apnea following treatment of head and neck cancer. Ear Nose Throat J 2007;86:101-103.

148. Antonescu-Turcu A, Parthasarathy S. CPAP and bi-level PAP therapy: new and established roles. Respir Care 2010;55:1216-1229.

149. Allen RP, Chen C, Garcia-Borreguero D, et al. Comparison of pregabalin with pramipexole for restless legs syndrome. N Engl J Med 2014;370:621631.

150. Bassetti CL, Bornatico F, Fuhr P, et al. Pramipexole versus dual release levodopa in restless legs syndrome: a double blind, randomised, cross-over trial. Swiss Med Wkly 2011;141:w13274.

151. Ferini-Strambi L, Aarskog D, Partinen M, et al. Effect of pramipexole on RLS symptoms and sleep: a randomized, double-blind, placebo-controlled trial. Sleep Med 2008;9:874-881.

152. Kaplan PW, Allen RP, Buchholz DW, Walters JK. A double-blind, placebocontrolled study of the treatment of periodic limb movements in sleep using carbidopa/levodopa and propoxyphene. Sleep 1993;16:717-723.

153. Manconi M, Ferri R, Zucconi M, et al. Pramipexole versus ropinirole: polysomnographic acute effects in restless legs syndrome. Mov Disord 2011;26:892-895.

154. Montplaisir J, Nicolas A, Denesle R, Gomez-Mancilla B. Restless legs syndrome improved by pramipexole: a double-blind randomized trial. Neurology 1999;52:938-943.

155. Oertel WH, Stiasny-Kolster K, Bergtholdt B, et al. Efficacy of pramipexole in restless legs syndrome: a six-week, multicenter, randomized, doubleblind study (effect-RLS study). Mov Disord 2007;22:213-219.

156. Trenkwalder C, Garcia-Borreguero D, Montagna $P$, et al. Ropinirole in the treatment of restless legs syndrome: results from the TREAT RLS 1 study, a 12 week, randomised, placebo controlled study in 10 European countries. J Neurol Neurosurg Psychiatry 2004;75:92-97.

157. Walters AS, Ondo WG, Dreykluft T, et al. Ropinirole is effective in the treatment of restless legs syndrome. TREAT RLS 2: a 12-week, doubleblind, randomized, parallel-group, placebo-controlled study. Mov Disord 2004;19:1414-1423.

158. Berger AM. Update on the state of the science: sleep-wake disturbances in adult patients with cancer. Oncol Nurs Forum 2009;36:E165-177.

159. Harsora P, Kessmann J. Nonpharmacologic management of chronic insomnia. Am Fam Physician 2009;79:125-130.

160. Jungquist CR, O'Brien C, Matteson-Rusby S, et al. The efficacy of cognitive-behavioral therapy for insomnia in patients with chronic pain. Sleep Med 2010;11:302-309.

161. Howell D, Oliver TK, Keller-Olaman S, et al. Sleep disturbance in adults with cancer: a systematic review of evidence for best practices in assessment and management for clinical practice. Ann Oncol 2013.

162. Garland SN, Carlson LE, Stephens AJ, et al. Mindfulness-based stress reduction compared with cognitive behavioral therapy for the treatment of insomnia comorbid with cancer: a randomized, partially blinded, noninferiority trial. J Clin Oncol 2014;32:449-457.

163. Kim SW, Shin IS, Kim JM, et al. Effectiveness of mirtazapine for nausea and insomnia in cancer patients with depression. Psychiatry Clin Neurosci 2008;62:75-83.

164. Stewart SA. The effects of benzodiazepines on cognition. J Clin Psychiatry 2005;66 Suppl 2:9-13.

165. US Food and Drug Administration. Zolpidem Containing Products: Drug Safety Communication: FDA Requires Lower Recommended Doses. 2013. Available at: http://www.fda.gov/safety/medwatch/safetyinformation/ safetyalertsforhumanmedicalproducts/ucm334738.htm. Accessed March 3, 2014.

166. Bruera E, Fainsinger R, MacEachern T, Hanson J. The use of methylphenidate in patients with incident cancer pain receiving regular opiates. A preliminary report. Pain 1992;50:75-77.

167. 2011 Physicians' Desk Reference (ed 65). Montvale, NJ: PDR Network, LLC; 2010.

168. Diagnostic and statistical manual of mental disorders (ed 4th). Washington, DC: American Psychiatric Association; 1994.

169. Bush SH, Kanji S, Pereira JL, et al. Treating an Established Episode of Delirium in Palliative Care: Expert Opinion and Review of the Current Evidence Base With Recommendations for Future Development. J Pain Symptom Manage 2014.

170. Irwin SA, Pirrello RD, Hirst JM, et al. Clarifying delirium management: practical, evidenced-based, expert recommendations for clinical practice. J Palliat Med 2013;16:423-435.

171. Hosie A, Davidson PM, Agar M, et al. Delirium prevalence, incidence, and implications for screening in specialist palliative care inpatient settings: a systematic review. Palliat Med 2013;27:486-498. 
172. de la Cruz M, Fan J, Yennu S, et al. The frequency of missed delirium in patients referred to palliative care in a comprehensive cancer center. Support Care Cancer 2015.

173. Breitbart W, Alici Y. Evidence-based treatment of delirium in patients with cancer. J Clin Oncol 2012;30:1206-1214.

174. Zimmerman KM, Salow M, Skarf LM, et al. Increasing anticholinergic burden and delirium in palliative care inpatients. Palliat Med 2014;28:335341.

175. Devlin JW, Roberts RJ, Fong JJ, et al. Efficacy and safety of quetiapine in critically ill patients with delirium: a prospective, multicenter, randomized, double-blind, placebo-controlled pilot study. Crit Care Med 2010;38:419_ 427.

176. Grover S, Mattoo SK, Gupta N. Usefulness of Atypical Antipsychotics and Choline Esterase Inhibitors in Delirium: A Review. Pharmacopsychiatry 2011.

177. Maher AR, Maglione M, Bagley S, et al. Efficacy and comparative effectiveness of atypical antipsychotic medications for off-label uses in adults: a systematic review and meta-analysis. JAMA 2011;306:1359-1369.

178. Lacasse H, Perreault MM, Williamson DR. Systematic review of antipsychotics for the treatment of hospital-associated delirium in medically or surgically ill patients. Ann Pharmacother 2006;40:1966-1973.

179. Jacobson SA. Delirium in the elderly. Psychiatr Clin North Am 1997;20:91-110.
180. Caraceni A, Nanni O, Maltoni M, et al. Impact of delirium on the short term prognosis of advanced cancer patients. Italian Multicenter Study Group on Palliative Care. Cancer 2000;89:1145-1149.

181. Kehl KA. Treatment of terminal restlessness: a review of the evidence. J Pain Palliat Care Pharmacother 2004;18:5-30.

182. Weeks JC, Cook EF, O'Day SJ, et al. Relationship between cance patients' predictions of prognosis and their treatment preferences. JAMA 1998;279:1709-1714.

183. Smith TJ, Dow LA, Virago EA, et al. A pilot trial of decision aids to give truthful prognostic and treatment information to chemotherapy patients with advanced cancer. J Support Oncol 2011;9:79-86.

184. Wright AA, Zhang B, Ray A, et al. Associations between end-of-life discussions, patient mental health, medical care near death, and caregiver bereavement adjustment. JAMA 2008;300:1665-1673.

185. Smith TJ, Swisher K. Telling the truth about terminal cancer. JAMA 1998;279:1746-1748.

186. Mack JW, Wolfe J, Cook EF, et al. Hope and prognostic disclosure. J Clin Oncol 2007;25:5636-5642.

187. Liu PH, Landrum MB, Weeks JC, et al. Physicians' propensity to discuss prognosis is associated with patients' awareness of prognosis for metastatic cancers. J Palliat Med 2014;17:673-682. 


\section{Individual Disclosures of the NCCN Palliative Care Panel}

\begin{tabular}{|c|c|c|c|c|}
\hline Panel Member & $\begin{array}{l}\text { Clinical Research } \\
\text { Support/Data Safety } \\
\text { Monitoring Board }\end{array}$ & $\begin{array}{l}\text { Scientific Advisory } \\
\text { Boards, Consultant, } \\
\text { or Expert Witness }\end{array}$ & $\begin{array}{l}\text { Promotional } \\
\text { Advisory } \\
\text { Boards, } \\
\text { Consultant, } \\
\text { or Speakers } \\
\text { Bureau }\end{array}$ & $\begin{array}{l}\text { Date } \\
\text { Completed }\end{array}$ \\
\hline Amy Alvarez-Perez, MD & None & None & None & $6 / 26 / 15$ \\
\hline Anthony Back, MD & None & None & None & $4 / 14 / 15$ \\
\hline Justin N. Baker, MD & None & None & None & $7 / 26 / 15$ \\
\hline Anna C. Beck, MD & Pfizer Inc. & None & None & $7 / 15 / 15$ \\
\hline Susan Block, MD & Branta Foundation & None & None & $7 / 16 / 15$ \\
\hline Shalini Dalal, MD & None & None & None & $7 / 08 / 15$ \\
\hline Maria Dans, MD & None & None & None & $6 / 15 / 15$ \\
\hline Thomas R. Fitch, MD & None & None & None & $6 / 17 / 15$ \\
\hline Jennifer Kapo, MD & Smilow Cancer Hospital & None & None & $8 / 03 / 15$ \\
\hline Jean S. Kutner, MD, MSPH & $\begin{array}{l}\text { AHRQ; American Cancer } \\
\text { Society; National } \\
\text { Heart Lung and Blood } \\
\text { Institute; National } \\
\text { Institute of Nursing } \\
\text { Research; National } \\
\text { Institute on Aging; and } \\
\text { PCORI }\end{array}$ & Institute of Medicine & None & $6 / 15 / 15$ \\
\hline Elizabeth Kvale, MD ${ }^{a}$ & None & None & None & $8 / 04 / 15$ \\
\hline Michael Levy, MD, PhD & None & None & None & $4 / 14 / 15$ \\
\hline Sumathi Misra, MD & None & $\begin{array}{l}\text { Legal expert for } \\
\text { malpractice suits }\end{array}$ & None & $8 / 04 / 15$ \\
\hline William Mitchell, MD & Pfizer Inc. & None & None & $4 / 14 / 15$ \\
\hline Diane G. Portman, MD & None & None & None & $4 / 14 / 15$ \\
\hline Todd M. Sauer, MD & None & None & None & $11 / 12 / 14$ \\
\hline Thomas Smith, MD ${ }^{\mathrm{a}, \mathrm{b}}$ & $\begin{array}{l}\text { Competitive } \\
\text { Technologies, Inc. } \\
\text { (makers of Scrambler } \\
\text { therapy) }\end{array}$ & None & None & $4 / 14 / 15$ \\
\hline David Spiegel, MD & $\begin{array}{l}\mathrm{NCl} \text {; and National Center } \\
\text { for Complementary and } \\
\text { Alternative Medicine }\end{array}$ & $\begin{array}{l}\text { Campbell, Erickson, } \\
\text { Ference \& Hall; } \\
\text { County of Santa } \\
\text { Clara; Fabian and } \\
\text { Clendenin; Law } \\
\text { Office of John } \\
\text { Halley; and PeerWell }\end{array}$ & None & $6 / 26 / 15$ \\
\hline Linda Sutton, MD & GW Pharmaceuticals & None & None & $7 / 15 / 15$ \\
\hline Eytan Szmuilowicz, MD & None & None & None & $7 / 28 / 15$ \\
\hline Robert M. Taylor & None & None & None & $7 / 29 / 15$ \\
\hline Jennifer Temel, MD & Helsinn Therapeutics, Inc. & None & None & $6 / 04 / 15$ \\
\hline Roma Tickoo, MD, MPH & None & None & None & $3 / 05 / 15$ \\
\hline Susan G. Urba, MD & None & Eisai Inc. & None & $9 / 04 / 15$ \\
\hline Elizabeth Weinstein, MD & None & None & None & $12 / 07 / 15$ \\
\hline Finly Zachariah, MD & None & None & None & $5 / 05 / 15$ \\
\hline
\end{tabular}

aThe following individuals have disclosed that they have an Employment/Governing Board, Patent, Equity, or Royalty conflict:

Jean Kutner MD, MSPH: American Academy of Hospice and Palliative Medicine

Elizabeth Kvale, MD: Aspire Health Care

Thomas Smith, MD: American Academy of Hospice and Palliative Medicine, and UnitedHealthcare

${ }^{b}$ The following individuals have disclosed that they have a Spouse/Domestic Partner/Dependent Potential Conflict:

Thomas Smith, MD: UnitedHealthcare

The NCCN Guidelines staff have no conflicts to disclose. 